\title{
Poverty and public services in developing-country cities
}

Paul C. Hewett

Population Council

Mark R. Montgomery

Population Council

Follow this and additional works at: https://knowledgecommons.popcouncil.org/departments_sbsr-pgy

Part of the Demography, Population, and Ecology Commons, International Public Health Commons, and the Urban Studies and Planning Commons

How does access to this work benefit you? Let us know!

\section{Recommended Citation}

Hewett, Paul C. and Mark R. Montgomery. 2001. "Poverty and public services in developing-country cities," Policy Research Division Working Paper no. 154. New York: Population Council. 


\section{Poverty and Public Services in D eveloping-C ountry Cities}

Paul C. Hewett

Mark R. Montgomery

2001 No. 154 


\title{
Poverty and Public Services in Developing-Country Cities
}

\author{
Paul C. Hewett \\ Mark R. Montgomery
}

Paul C. Hewett is Associate, Policy Research Division, Population Council. Mark R. Montgomery is Senior Associate in the Policy Research Division and Professor of Economics, State University of New York at Stony Brook. Contact information for first author: Paul C. Hewett, Policy Research Division, Population Council, One Dag Hammarskjold Plaza, New York, New York 10017; e-mail address: phewett@popcouncil.org. 


\section{Abstract}

In developing countries, neither households nor firms can count on having access to basic public services. Households lacking adequate water supply and sanitation face elevated health risks; firms and micro-enterprises lacking electricity and water face higher costs of production. For reasons such as these, the inadequate provision of public services can compromise health, hinder economic growth, and stymie efforts to reduce poverty. This paper examines the availability of services in the cities and towns of developing countries, using data drawn from the Demographic and Health Surveys. Particular attention is given to the urban poor, who will form a group of increasing numerical and policy significance as levels of urbanization rise. We find that wide rural-urban gaps remain in service delivery, and that smaller cities — where about half of urban residents live-are notably under-served by comparison with larger cities. Poor urban households are much less likely than other urban households to enjoy access to public services. Inequities such as these underscore the need for continued public sector investments in service delivery. But the political economy of urban governance is changing in a way that may well frustrate efforts to improve services. Across the developing world, national governments are increasingly decentralizing their service delivery functions to lower tiers of government, often without making commensurate transfers of funds or revenue-raising authority. As nation-states recede from the local scene, local governments may be left without the means to fill the gaps in service delivery.

This material may not be reproduced without written permission from the authors. 
For the forseeable future, world population growth will be mainly concentrated in the cities of developing countries. According to the United Nations (2000), by the year 2030 the world's population will exceed today's total by 2.06 billion persons, and some 1.94 billion of these will be added to the urban areas of low-income countries. By 2030, it is believed, all developing regions will have crossed the half-way point to become more urban than rural. Even if a generous allowance is made for the variety of urban definitions and the uncertainties of demographic forecasts, the central message remains clear: soon it will no longer be possible to speak of low-income countries as being mainly rural.

If these are the prospects in view, then researchers concerned with poverty and opportunity must increasingly set their concerns in urban contexts. The provision of public services - water, sanitary waste disposal, and electricity — is central to both urban poverty reduction and economic growth. Where health is concerned, urban populations suffer from the twin disadvantages of crowding and dependence on common resources; in the absence of safe water supplies and adequate sanitation, they would be exposed to greater risks of communicable disease than would spatially dispersed rural populations (Preston and van de Walle 1978; Johansson and Mosk 1987; Van Poppel and van der Heijden 1997; Brockerhoff and Hewett 2000). Water and electricity are also inputs into production. When these services are reliably supplied, they allow urban micro-enterprises and firms to reap the advantages of agglomeration and scale economies (see, among others, Montgomery 1987, 1988; Davis et al. 2001). Public services are sufficiently important that they are often considered to be basic needs.

But in some poor regions of the developing world, the pace of city growth is running well ahead of the capacity to extend basic public services. In discussions of urban growth, it is the largest cities that come readily to mind - cities of the size of Cairo, Bangkok, and São Paulo-and smaller cities are too easily overlooked. This is unfortunate, for cities with fewer than 500,000 residents account for roughly half of the urban population of developing countries, and will continue to do so well into this century (United Nations 2000). Furthermore, the growth rates of small cities typically exceed those of larger cities, although there is considerable variation around this general tendency (United Nations 2000: 90). A balanced depiction of service delivery therefore must give proportionate attention to small cities.

In this analysis, we assess the state of service provision in the cities and towns of 43 developing countries. Our main focus is on the urban areas of these countries, but 
where possible we make comparisons with rural areas as well. We study the effects of poverty at two levels: cross-nationally, by examining countries across a range of national incomes per capita; and within countries, by comparing the urban poor with other urban residents. As will be seen, there are striking differences in service provision in each of these dimensions. In addition, we show that smaller cities are badly served by comparison with larger cities.

In the next section, we describe the data we shall use-they are drawn from the Demographic and Health Surveys (DHS) — and show how the provision of piped water, flush toilets, and electricity varies between rural and urban areas, and by city size within the urban sector. Regional variation in service delivery will be shown to be substantial, even holding constant the level of national income per capita. Also examined here are the changes in service provision that have taken place between the rounds of DHS surveys for the 18 countries with more than one such survey. ${ }^{1}$

We then take up the question of whether, and to what extent, poor urban households are under-served by comparison with other urban households. Because the DHS program gathers no data on incomes or expenditures as such, measures of poverty are limited to those that can be fashioned from a small set of proxy variables, including ownership of consumer durables and crude indexes of the quality of housing. We explore two approaches to distilling the proxies into a single living standards index: principal components and confirmatory factor analysis. The principal components method was deployed by Filmer and Pritchett (1999) in a study of schooling; it was sharply criticized on theoretical grounds by Montgomery et al. (2000) but then vigorously defended by Filmer and Pritchett (2001). Sahn and Stifel (2000) and Montgomery et al. (2000) argued that latent variables models, of which confirmatory factor analysis is one example, are bettergrounded in theoretical terms, and present possibilities for generalization and extension that are not offered by principal components. Sahn and Stifel (2000) applied factor analysis to DHS data from Africa, and obtained encouraging results. To date, however, there has been no comprehensive comparison of the two methods. Here we set out their similarities and differences in analytic terms, and show how living standards indexes derived from the two methods vary empirically with the education of the household head and with city size.

\footnotetext{
${ }^{1}$ See Table A.1 for a list of countries and survey years.
} 
After describing the elements of principal components and factor analysis, we apply these methods to determine the access of the urban poor to public services. The analysis in this section shows that the urban poor have decidedly inferior access to services by comparison with other urban residents. Their access is superior, however, to that of the average rural resident. Indeed, our findings make a strong case for a continued emphasis on rural populations, who exhibit clear evidence of absolute disadvantage, together with a new emphasis on the urban poor.

We conclude by considering what levels of government bear responsibility for improving urban service delivery. This is an increasingly complicated matter, because across the developing world, national governments are rapidly decentralizing their functions, and some of their revenue-raising authority, to state, metropolitan, and local units of government (UNCHS 1996). As Manor (1999: 1) writes,

Decentralization has quietly become a fashion of our time. It is being considered or attempted in an astonishing diversity of developing and transitional countries ... by solvent and insolvent regimes, by democracies (both mature and emergent) and autocracies, by regimes making the transition to democracy and by others seeking to avoid that transition, by regimes with various colonial inheritances and by those with none. It is being attempted where civil society is strong, and where it is weak.

Often, however, the transfer of responsibilities from national to local levels is being carried out without an adequate transfer of resources, leaving local governments without the means to extend public services in their jurisdictions (UNCHS 1996: Chapter 5). In some cases, local community-based organizations and nongovernmental organizations are attempting to fill the service delivery gap. To illustrate the problem, we will describe the current state of affairs in Accra, Ghana, where there is great confusion about how far governmental responsibilities now extend, and what responsibilities are left in the hands of local civil society (Gough and Yankson 2001).

\section{Public Services: Measures and Variation}

Data on public services are gathered by the Demographic and Health Surveys program in its household interview schedules. There is some variation from survey to survey in how access to services is measured, but the DHS program has imposed a coding scheme that keeps this variation reasonably well contained. By choosing to define broad cate- 
gories of access - see Box 1 for the scheme adopted here-we have organized the data in a way that should permit valid comparisons across countries and over time, at the cost of omitting some country-specific details.

To explore differences in service provision by city size, we have linked the sampling cluster identifiers found in the DHS data sets to the city population counts published in various years of the United Nations Demographic Yearbook. This was not an easy task, because the DHS program does not release geographic identifiers that identify cities of residence by name. Instead, it groups cities into broad categories- the "large and capital cities," which contain over 1 million persons, smaller cities in the range from 50,000 to 1 million population, and a residual category of towns - and this loose characterization often fails to pinpoint a specific city of residence. Using all available geographic information in each DHS data set (region of residence is generally recorded, although it, too, can be described in overly broad terms), we endeavored to match each sampling cluster to a specific city of residence, where this was possible, and where not, to a candidate set of cities. (The details of the procedure are given in Montgomery et al. 2001.) The city population counts were either taken directly from the United Nations Demographic Yearbook, or calculated as averages when the cluster could only be linked to a set of cities. ${ }^{2}$ Because the city size estimates are imprecise, we group them into ranges that are narrow enough to convey information, but not so narrow as to be compromised by the errors introduced in the process of matching.

\section{Differences by region and city size}

Figure 1 shows how access to services varies between rural and urban areas and, within the urban areas, by city size. The figure shows the average percentage of households with access, this average being calculated across all DHS surveys. Rural areas are indicated in the darkest bars, and urban areas, classified in ranges of population size, are shown in progressively lighter bars.

The urban advantage is evident at a glance. Consider the sub-Saharan countries with DHS surveys. In these countries only a small minority of rural households (5 percent in the average survey) receives electricity, whereas in the largest cities of the region (those in

\footnotetext{
${ }^{2}$ The aim was to employ city population size as recorded for 1990 or the closest year to it, with preference given to the size of the urban agglomeration and the population of the city proper being used only if an agglomeration figure was lacking. When a DHS cluster was linked to a set of cities, we assigned to the cluster a city size equal to the weighted averages of the city populations in the set, using the United Nations city sizes themselves as weights.
} 
BOX 1 Measures of access to public services available in the Demographic and Health Surveys

Drinking water For these analyses, a household is said to have adequate access to drinking water if water is delivered to the household through in-residence pipes or an in-residence well, the latter accounting for a small proportion of cases. Households lacking such access draw their water from neighborhood sources, usually standpipes or wells; water can also be purchased from vendors and tanker trucks; and it can be taken from other sources, such as from open streams and rainwater. Unfortunately, no data are collected in DHS surveys on the money costs of water, the weekly or daily variability of supply, and perceived levels of contamination, all of which would be important considerations in urban areas.

Many countries have fielded a DHS question on the time required to fetch water and return, a potentially useful indicator that summarizes distance to a water source and congestion (waiting time) costs. The measure is available in most of the DHS surveys used here. In other research (Montgomery et al. 2001) we have analyzed this measure and obtained results very similar to those presented below.

Waste disposal The household's access to an adequate method of waste disposal is indicated by whether it uses a flush toilet. Alternatives include use of a pit toilet or latrine, and a variety of other methods of disposal, such as "throw-aways" and deposits in the bush.

Some DHS surveys include additional questions on the privacy of access to flush toilets, pit toilets, and latrines, which could show how many households must share such facilities. Unfortunately, not enough surveys have included these questions to justify exploring them. No information is gathered on the frequency with which facilities other than flush toilets are cleaned, or on the time costs of access in the case of shared facilities.

Electricity Access to electricity is measured through a "yes-no" question that again omits the dimensions of cost, reliability, and adequacy.

Lacks 3 services We include a summary measure of disadvantage in access, indicating that the household lacks piped water, a flush toilet, and electricity. 


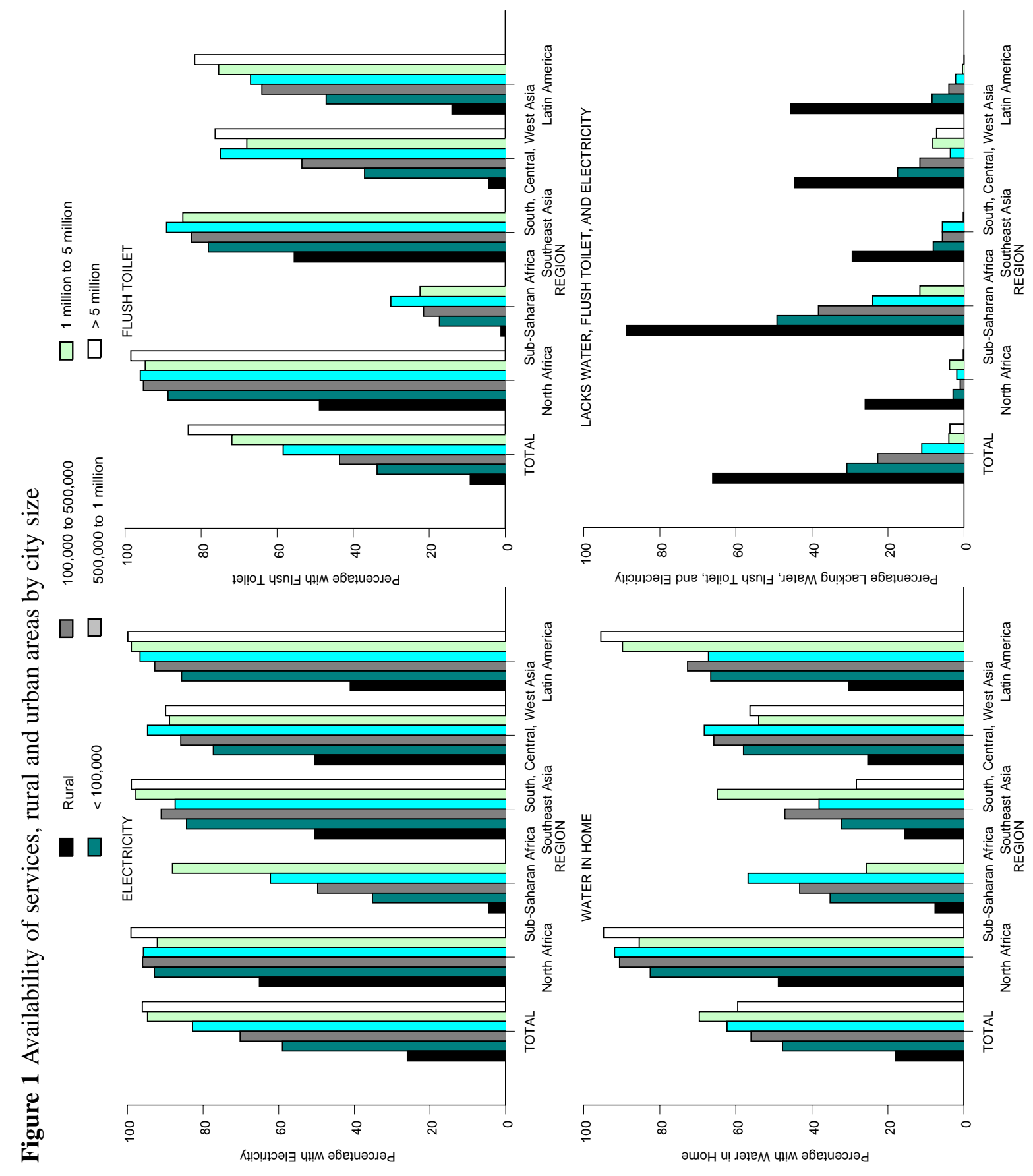


the 1-5 million range) electricity is available to 88 percent of households. ${ }^{3}$ The provision of piped water to the home is also far more likely in urban areas, as is access to flush toilets. (Access to flush toilets is, of course, strongly influenced by the provision of piped water.) The urban advantage is especially striking when one considers the percentages of households lacking all three services-in each region, rural households are far more likely than urban to suffer from this sort of disadvantage. In the rural parts of sub-Saharan Africa, nearly 90 percent of households lack access to the three basic services.

The city size differences in service provision are perhaps not so vivid as the urbanrural differences, but they, too, can be substantial. Apart from North Africa, where electricity is almost universally available in urban areas irrespective of their size, the differences between small and large cities are noteworthy. The sub-Saharan African countries again provide a case in point-electricity is available in only 35 percent of cities under 100,000 in size, as against the aforementioned 88 percent in the largest cities of the region. A similar situation prevails in Latin American countries, although here the average level of provision is much higher. Some 86 percent of households in the smallest Latin American cities have electricity, but nearly all households (over 99 percent) have access in the largest cities. The provision of piped water to the home is also more common in the large cities of Latin America than in smaller cities, although in other regions these differences are irregular. Much the same can be said of access to flush toilets, which is generally more likely in large cities than in small. The composite measure of disadvantage-which indicates that all three services are lacking - also tends to fall with city size.

To be sure, these gradients in service delivery by city size are not always uniform, and each region presents minor deviations from the general pattern of increasing access with city size. Indeed, it would be surprising if city population size alone could stand as a proxy for the complex configurations of political, economic, and technical factors involved in the delivery and management of public services. Nevertheless, the broad outlines of the findings are clear enough: residence in a small city is associated with inferior access to basic services.

The health externalities implied by poor water supply and waste disposal depend on population density, insofar as density affects the likelihood of contamination. Viewed in this light, the urban-rural and city size differences deserve further discussion. Figure 1 showed that rural households are much less likely to have water piped to their homes,

\footnotetext{
${ }^{3}$ Lagos is omitted from the figure because Nigeria did not gather services data in the household module of its DHS survey.
} 
and relatively few rural households (outside Indonesia and the Philippines, which are the only countries surveyed by the DHS in Southeast Asia) enjoy the use of flush toilets. For waste disposal, however, rural households are more likely than urban to use pit toilets and latrines (results not shown, but see Montgomery et al. 2001). This might be taken as still more evidence of rural disadvantage - but a well-constructed and maintained pit latrine can provide the same health advantages as a flush toilet, provided that water is available for washing. The use of "other" methods of waste disposal also merits comment. In small, uncrowded rural communities, defecation in the bush or in the open can present little risk of human contact with feces or contamination of water sources. In crowded urban areas, by contrast, open defecation and "throw-aways" may present substantial health risks. ${ }^{4}$

Trends in service provision can be explored in the subset of DHS countries having more than one survey. The time spans involved-about 2.5 years between surveys, on average - are perhaps too brief for the results to be given much weight. Still, it is noteworthy that even over such short periods, these developing countries made discernible progress in extending public services. For electricity, where we can inspect 17 pairs of surveys, the average increase in provision between surveys was 5.9 percentage points in rural areas and 6.3 points in urban. Improvements in piped water and access to flush toilets were smaller, with gains on the order of 2 percentage points in rural areas and less than 1 point in urban. Sub-Saharan Africa recorded the smallest improvements in water and toilet provision, as would be expected given its chronic economic malaise, although its disadvantage is less apparent in urban electrification. In short, the limited results available on trends in service provision suggest modest improvements over time for the DHS countries permitting comparison. ${ }^{5}$

\section{Differences by national income per capita}

Figures 2 and 3 show how access to drinking water varies with national income per capita. The results for all surveys are shown in the left panels of the figures; the right panels depict the associations within regions. To summarize the data in the left panel, we

\footnotetext{
${ }^{4}$ We thank David Satterthwaite for these observations. As documented in Montgomery et al. (2001), significant percentages of urban households use "other" methods of waste disposal in sub-Saharan Africa, in South, Central, and West Asia, and even in Latin America.

${ }^{5}$ It would be useful to set these short-run changes against a background of longer-run trends. Unfortunately, the trend data available are of very doubtful reliability. UNCHS (1996: Chapter 8) and World Bank (1994) review what is known of longer-run trends in service provision in selected countries. Their estimates are obtained from disparate sources, including surveys, expert judgments, and impressionistic accounts. They are not strictly comparable to the DHS estimates described above.
} 

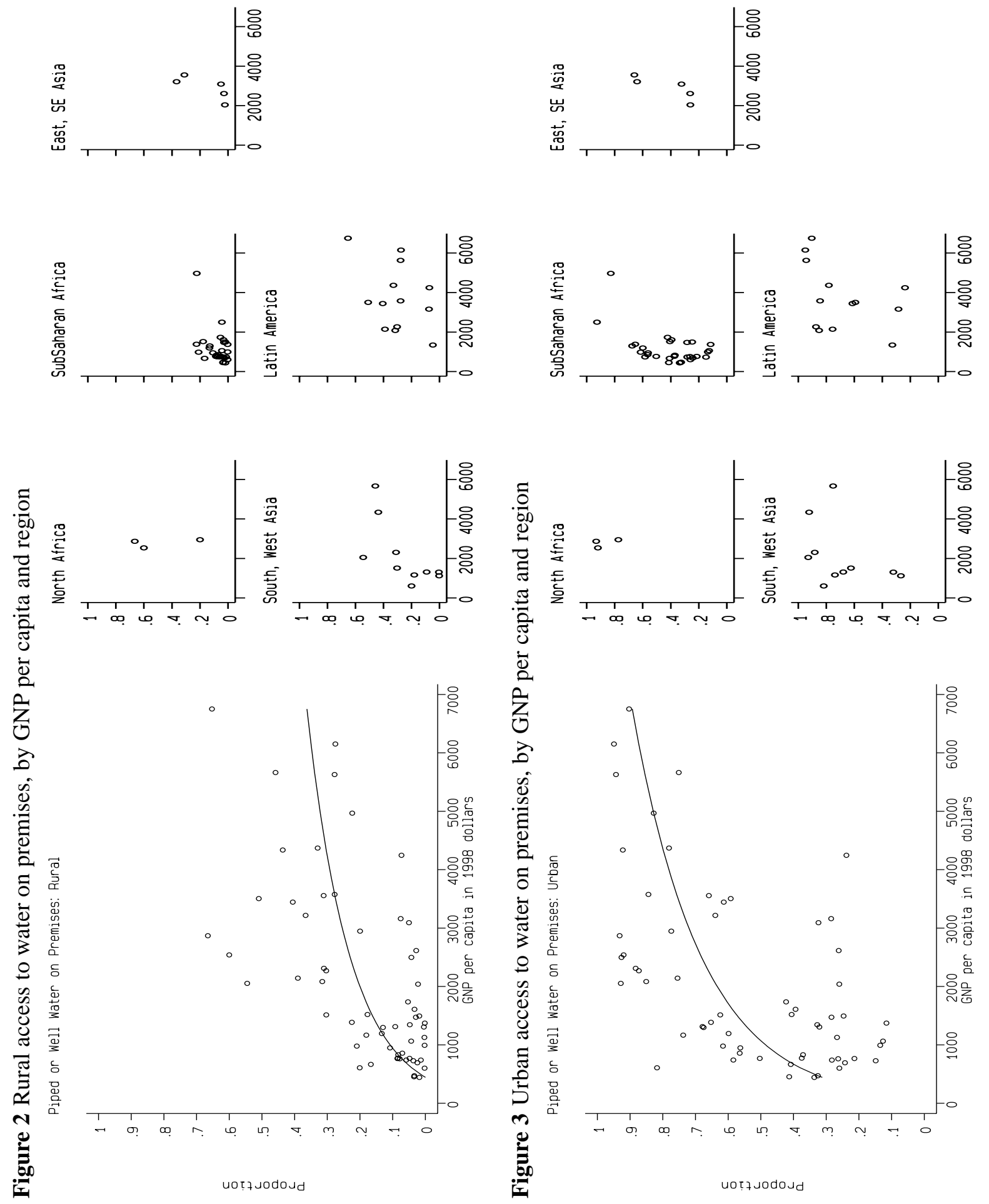
sketch the results of a descriptive regression analysis in which access to water is predicted by the log of income per capita. ${ }^{6}$

The left panels of these figures seem to indicate a strong positive association between the level of national income per capita and access to piped water. In both rural and urban areas, the likelihood of access rises with national income. By comparing Figures 2 and 3, one can see that the regression line for rural areas lies well below that for urban areas at each level of income. The provision of electricity and access to flush toilets also exhibit strong associations with national per capita income levels (figures not shown).

It is tempting to interpret these associations with national income as the result of higher government revenues and better management capacities. Surely that is a tenable interpretation, but the link to incomes may also reflect unexplained regional factors. The set of graphs in the right panel of Figure 2, for example, shows that the positive association between rural piped water and income remains clearly apparent only in Latin America and in the diverse countries of South, Central, and West Asia. In the other regions, the association is either greatly attenuated or disappears altogether. Much the same pattern is seen in Figure 3, where the urban areas are considered. Higher national income may well be an enabling factor in service provision, but it seems that other economic and political considerations also need to be taken into account.

\section{Summary}

Evidently, the average urban household in these countries enjoys better access to services than the average rural household. This is hardly surprising - it is the result of differences in socioeconomic composition, technical and economic factors that determine the costs of service delivery, and long-standing priorities in government infrastructural investment (World Bank 1994). Concentrations of middle- and upper-income groups in urban areas undoubtedly drive up the urban averages, insofar as individual access improves with ability to pay, and government revenues rise with individual incomes. Another source of urban advantage lies in the significant economies of scale, scope, and proximity that - at least in principle-reduce the costs per user of some public services in urban areas (e.g., Montgomery 1988).

No one doubts that government investment priorities have often favored large cities, and this tendency has enabled some critics to level charges of "urban bias" in service

\footnotetext{
sion.

${ }^{6}$ To protect the summary curves against overly influential outliers, we use the method of median regres-
} 
provision. The charge is difficult either to support or to refute. It is uncertain whether bias-free investment strategies would still concentrate scarce capital resources in cities, given the lower average costs of service provision and the expectation of greater economic benefits (World Bank 1994). Less often noted in discussions of urban bias is that the smaller cities-particularly those under 100,000 in population-have been ill-served by comparison with larger cities. Moreover, the crude services measures available do not allow consideration of the variability and adequacy of urban services. What does it mean to a city resident to have access to electricity, for example? Might it mean that current flows every other day, or for a few hours each day, or continuously but at such low levels that electrical appliances often fail to work? Were the DHS program to field survey questions on these dimensions of service delivery, we might well find that the urban advantage has been overstated.

\section{Proxy Measures of Poverty}

We now consider the situation of the urban poor, a group that should increasingly attract attention as developing countries urbanize and socioeconomic inequality comes to be defined mainly in terms of the intra-urban distribution of living standards. To address the question of poverty and its link to basic services, we are obliged to consider difficult issues of measurement and methodology.

A perennial problem in demographic research on poverty is the lack of cross-nationally comparable data sets that contain defensible measures of poverty as well as demographic indicators, and that are drawn from samples large enough to shed light on urban areas. With the notable exception of the World Bank's Living Standards Measurement Surveys and RAND's Malaysian and Indonesian Family Life Surveys, data on household incomes and consumption expenditures are seldom found in the same data sets as measures of public services and demographic behavior. Obtaining accurate data on incomes and expenditures is a demanding, time-consuming task admitting of few shortcuts (Deaton 2001). Given the weight they must place on other issues, demographic surveys have rarely attempted to gather such data, and the Demographic and Health Surveys are no exception to this rule. ${ }^{7}$ Researchers interested in linking poverty to demography have had little recourse but to use proxy variables for poverty.

\footnotetext{
${ }^{7}$ One survey, the 1994 Indonesia DHS, fielded an experimental module on household consumption expenditures in about half of the surveyed households.
} 
Montgomery et al. (2000) review the issues associated with the use of such proxy variables, with reference to models of fertility, mortality, and children's schooling. A thorough discussion would take us outside the bounds of the present paper, but we should emphasize several points made in the earlier article. First, researchers have often constructed living standards indexes by combining measures of access to public services with indicators of household ownership of consumer durables and housing quality. That is not an approach open to us here, given our interest in determining whether the poor have adequate access to services. Inadequate access to services is of interest in itself, capturing aspects of disadvantage that are not easily seen in measures of income or expenditures. For example, Brockerhoff (1990) found that Senegalese families without access to hygienic sanitation and clean water had a 30 percent increased risk of infant and child mortality. These findings were further reinforced by Brockerhoff and Hewett (2000), who also found significant increases in child mortality when piped water and electricity were unavailable to the household. Such studies give policymakers a clear sense of the benefits of improving access to public services. The force of such messages would be diminished if services were to be combined with a variety of other measures in a single living standards index.

Second, there is little consensus in the literature about how best to combine the grab-bag of living standards measures found in the usual demographic survey. Most researchers would agree that ownership of consumer durables ought to be considered, but some have also used indicators of household productive assets, such as holdings of land and animals. These might well be appropriate measures in rural settings, but are either inappropriate for urban households or (as in the case of land ownership) extremely difficult to measure in urban contexts. Husband's occupation is also used on occasion, although this opens the question of how to proceed when no husband or partner is present in the household. Likewise, education is often offered as a proxy for living standards, but it is too powerful a determinant of demographic behavior to be consigned to this narrow category.

The third and perhaps most vexing problem — clearly evident in the case of educationis that a single variable can play "dual roles" in a demographic model (Montgomery et al. 2000). In a model of children's health, for instance, women's education represents not only the living standard of the household, but also its capacity to process information about health and possibly the social autonomy and decisionmaking authority needed to 
bring resources to bear when a child falls ill. Disentangling these roles is a difficult conceptual and statistical exercise; for education, one would require a means of separating the direct influence of education on behavior from its indirect influence as a living standards proxy. Strong and unpalatable statistical assumptions are needed to distinguish these influences.

With these problems in view, researchers using proxy variables have developed twostep approaches in which the first step involves a construction of a living standards index from the proxies, and in the second step the estimated index (or a measure derived from it) is inserted in the structural equation of interest. Two variants of the approach have emerged: Filmer and Pritchett (1999) advocate a simple but atheoretical method using principal components, whereas Sahn and Stifel (2000) argue that confirmatory factor analysis provides a firmer theoretical and statistical foundation.

Table 1 Number of DHS surveys, by region, with consumer durables and housing quality variables available ${ }^{\mathrm{a}}$

\begin{tabular}{llllll}
\hline & $\begin{array}{l}\text { North } \\
\text { Africa }\end{array}$ & $\begin{array}{l}\text { Sub- } \\
\text { Saharan } \\
\text { Africa }\end{array}$ & $\begin{array}{l}\text { Southeast } \\
\text { Asia }\end{array}$ & $\begin{array}{l}\text { South, } \\
\text { Central, } \\
\text { West Asia }\end{array}$ & $\begin{array}{l}\text { Latin } \\
\text { America }\end{array}$ \\
\hline $\begin{array}{l}\text { Consumer Durables } \\
\text { Refrigerator }\end{array}$ & 3 & 29 & 4 & 7 & 13 \\
Television & 3 & 28 & 5 & 10 & 13 \\
Radio & 3 & 30 & 4 & 10 & 13 \\
Bicycle & 3 & 30 & 5 & 9 & 10 \\
Motorcycle & 1 & 29 & 4 & 6 & 10 \\
Car & 1 & 29 & 5 & 6 & 11 \\
Housing Quality & & & & & \\
Number of sleeping rooms & 3 & 30 & 2 & 8 & 13 \\
Finished flooring & 3 & 30 & 5 & 8 & 13 \\
Total Number of $\quad$ DHS & 3 & 30 & 5 & 10 & 13 \\
Surveys & & & & & \\
\hline
\end{tabular}

${ }^{a}$ Includes only variables from the household files of DHS Phase II and III surveys.

We continue this line of research, hoping to clarify the differences between the two approaches and to assess their performance over the full range of Demographic and Health Surveys. We base our specifications on the list of consumer durables and housing measures shown in Table 1. The measures listed in this table are usually available in a DHS 
survey, although some countries lack one or two of them. Some DHS surveys include additional consumer items, e.g., possession of soap or a cooking stove, but we exclude these measures in the interest of achieving reasonable cross-country comparability.

We depart from Filmer and Pritchett $(1999,2001)$ and Sahn and Stifel (2000) in restricting our analyses to urban areas. It is not at all obvious that a single living standards index should be devised for urban and rural households combined, given the great differences in consumption patterns and prices between urban and rural areas. A safer approach, we believe, is to formulate a living standards index that is specific to urban populations.

\section{Principal components}

Here we explore the statistical foundations of the principal components and confirmatory factor methods, seeking to identify common elements as well as differences in the two approaches. We begin with the principal components approach. This method is decidedly more computational than statistical in spirit. Its starting-point is an exact decomposition of the covariance of a set of explanatory variables, whereby the covariance matrix is expressed as a sum of component matrices. The appeal of the method lies in the hope that, upon inspection, one or two of the components will be found sufficient to summarize "most" of the variability displayed by the original variables. Principal components is often regarded as a data reduction device, in that it allows a potentially large number of explanatory variables to be represented by a much smaller number of components (Dunteman 1989).

To understand the method, consider a set of $k$ explanatory variables $x_{i}$, where $x_{i}$ is a column vector and the $i$ subscript serves to index observations. (In our application, $x_{i}$ refers to the list of durables and housing quality measures for household $i$, as presented in Table 1.) The $x_{i}$ vectors are taken to have been centered so as to have zero mean in each of their $k$ elements. The empirical covariance matrix of the $x_{i}$ vectors is then

$$
\hat{V}=\frac{1}{n} \sum_{i=1}^{n} x_{i} x_{i}^{\prime}
$$

where $n$ is the sample size. ${ }^{8}$

The problem is how to choose a $k$-vector of weights $w$ in such a way as to maximize the variance of $w^{\prime} x_{i}$, which is a linear combination of the weights and the variables in

\footnotetext{
${ }^{8} \mathrm{An}$ implicit assumption is that the $x_{i}$ vectors are uncorrelated across households (the $i$ subscript) and homoskedastic.
} 
the $x_{i}$ vector. The variance of $w^{\prime} x_{i}$ is estimated by $w^{\prime} \hat{V} w$. For this problem to be welldefined, we must impose a normalization that keeps $w$ within bounds, and we therefore restrict the admissable $w$ to those that satisfy $w^{\prime} w=1$. The problem is thus posed as

$$
\max _{w: w^{\prime} w=1} w^{\prime} \hat{V} w
$$

The vector $w_{1}$ that solves this problem is the eigenvector of $\hat{V}$ that is associated with $\lambda_{1}$, the largest of $\hat{V}$ 's eigenvalues. It can be shown that $\lambda_{1}$ is also the maximum variance attained, that is, $\lambda_{1}=w_{1}^{\prime} \hat{V} w_{1}$. Succinct proofs of these propositions are given in Schott (1997: 104-110, Theorem 3.15).

With $w_{1}$ in hand, we can then address a second problem, how to choose another $w$ vector, orthogonal to the first, that maximizes $w^{\prime} \hat{V} w$. That is, we aim to choose $w$ so as to

$$
\max _{w: w^{\prime} w=1, w^{\prime} w_{1}=0} w^{\prime} \hat{V} w .
$$

The solution to this second problem is $w_{2}$, the eigenvector associated with the second largest of $\hat{V}$ 's eigenvalues (Schott 1997: Theorem 3.16). We can proceed in this fashion, choosing new vectors $w_{j}$ from a set orthogonal to all vectors $\left[w_{1}, \ldots, w_{j-1}\right]$ chosen previously, until we have finally exhausted the full set of $\hat{V}$ 's eigenvalues and eigenvectors. Because $\hat{V}$ is symmetric and positive definite, all of the eigenvalues $\lambda_{j}, j=1, \ldots, k$, are positive.

Gathering the $w_{j}$ eigenvectors in a $k \times k$ matrix $W$, and arranging their eigenvalues in a diagonal matrix $D$, we obtain

$$
\hat{V} W=W D
$$

and can then decompose the $\hat{V}$ matrix as

$$
\hat{V}=W D W^{\prime}=\sum_{j=1}^{k} \lambda_{j} w_{j} w_{j}^{\prime},
$$

owing to the fact that $W$ is an orthonormal matrix whose transpose is its inverse. The decomposition is exact, provided that all $k$ of the eigenvalues and eigenvectors are used.

Since $D=W^{\prime} \hat{V} W$, we may write

$$
\sum_{j=1}^{k} \lambda_{j}=\operatorname{trace} D=\operatorname{trace} \hat{V} W W^{\prime}=\operatorname{trace} \hat{V}=\sum_{j=1}^{k} \hat{v}_{j, j}
$$


a result that shows that the sum of the eigenvalues equals the sum of the variances of the variables in $x$. If $\hat{V}$ were to be defined from the outset as a correlation matrix, rather than as a covariance matrix, the sum of the eigenvalues would equal $k$, the number of variables. In this case, the average eigenvalue would be unity. ${ }^{9}$

Using these ingredients, we define and manipulate the principal components. The $j$-th principal component for observation $i$ is defined to be the linear combination

$$
p_{i, j}=w_{j}^{\prime} x_{i}
$$

All $k$ principal components for this observation can be placed into a column vector, such that

$$
p_{i}=\left[\begin{array}{c}
p_{i, 1} \\
p_{i, 2} \\
\vdots \\
p_{i, k}
\end{array}\right]=W^{\prime} x_{i}
$$

and the variance matrix of $p_{i}$ is then easily seen to be $D$, the diagonal matrix with the eigenvalues on the diagonal. Equation (2) can be inverted by multiplying by $W$, yielding

$$
x_{i}=W p_{i},
$$

in which the original $x_{i}$ vector is here re-expressed as a weighted combination of $k$ principal components.

It may seem that all these manipulations have accomplished very little. We began by considering $k$ explanatory variables $x_{i}$ with covariance matrix $\hat{V}$, and have found that they can be represented by an equal number of principal components $p_{i}$ having the diagonal matrix $D$ as their covariance matrix. If there is value in the principal components approach, it rests on two hopes: that a few principal components can be taken to adequately represent the full set of $k$ covariates, and that the elements of the most important eigenvectors (e.g., $w_{1}$ and $w_{2}$ ) will be found to have some substantive interpretation.

Nothing in the method guarantees that either hope will be rewarded. But in practice, it sometimes happens that the eigenvectors can be interpreted in socioeconomic terms, and

\footnotetext{
${ }^{9}$ See Dunteman (1989: 22) for a discussion of whether $\lambda_{j}=1.0$ is a statistically sensible benchmark. Schott (1997: 404-6) describes how, as with formal test statistics, the asymptotic distributions of eigenvalues and eigenvectors (suitably normalized) might be employed to establish appropriate benchmark values.
} 
Table 2 Explanatory power of principal components for three sets of covariates

\begin{tabular}{lccc}
\hline $\begin{array}{l}\text { DHS Surveys in } \\
\text { Region }\end{array}$ & $\begin{array}{l}\text { Consumer } \\
\text { Durables Only }\end{array}$ & $\begin{array}{l}\text { Durables and } \\
\text { Housing Quality }\end{array}$ & $\begin{array}{l}\text { Durables, Housing } \\
\text { Quality, and } \\
\text { Services }\end{array}$ \\
\hline \multicolumn{4}{r}{ Average Percentage of } \\
\multicolumn{4}{r}{ Variability Explained } \\
Average Number of Eigenvalues Exceeding & 38.5 & 34.8 & Unity \\
North Africa & 1.3 & 2.3 & 30.1 \\
Sub-Saharan Africa & 2.1 & 2.5 & 3.3 \\
Southeast Asia & 1.4 & 2.0 & 3.9 \\
South, Central, West & 1.5 & 2.2 & 3.4 \\
Asia & & & 3.7 \\
Latin America & 1.5 & 2.0 & 3.7 \\
\hline
\end{tabular}

${ }^{a}$ Source: DHS II and III household surveys using various specifications of the asset variables.

Table 1 lists the variables in each category.

often only a few of these eigenvectors are required to account for a high percentage of the "total variability" of $x_{i}$, where total variability is defined as the sum of the variances. ${ }^{10}$

In the studies that have used this technique (e.g., Filmer and Pritchett 1999, 2001), the first principal component $p_{i, 1}$ has been taken to represent the socioeconomic status of the $i$-th household. Whether this is a tenable interpretation depends on the degree of correlation among the observed $x_{i}$ variables. When the $x_{i}$ are closely associated, one or two principal components can account for most of their total variability. But when the $x_{i}$ are not so tightly bound together, the number of principal components required for an adequate summary can be large.

The problem can be seen in Table 2, which is based on the Demographic and Health Survey data. The table presents three specifications of $x_{i}$, and for each specification shows the percent of the total variability attributable to the first principal component. The Filmer-Pritchett specification, which uses the largest and most varied collection of $x_{i}$ covariates, is given in the third column of the table. As can be seen in this column, when $x_{i}$ includes consumer durables, access to services, and housing quality, only 30.1 percent of the total variability is explained, on average, by the first principal component.

\footnotetext{
${ }^{10}$ That is, total variability is $\sum_{j=1}^{k} \hat{v}_{j, j}$. As noted above, this sum equals $\sum_{j=1}^{k} \lambda_{j}$, the sum of the eigenvalues. Hence, $\lambda_{j} / \sum_{l=1}^{k} \lambda_{l}$ is the proportion of the total variability attributable to the $j$-th component.
} 
If $\lambda_{j}>1.0$ is taken to be the cutoff point, then 3-4 principal components are required to adequately summarize these data. By contrast, when the $x_{i}$ are restricted to the consumer durables only (the first column of Table 2 ), the percentage of variability explained by one principal component is much higher.

The problem was recognized by Filmer and Pritchett, but they faced a common dilemma in deciding whether to incorporate additional components. With respect to the second principal component, Filmer and Pritchett (1999: 89) conceded that "we do not know how to interpret this second principal component (especially in a consistent way across countries) and ignore it for now in an uneasy truce with the data." The rationale for excluding second and higher components might have been strengthened by standard statistical tests applied to their model of children's schooling, but they did not pursue this possibility further.

Lacking clear statistical criteria for selecting components, Filmer and Pritchett (2001) instead turned to indirect assessments of the meaning of the first component, examining its correlations with other covariates in other data sets and giving special attention to its correlation with consumption expenditures. ${ }^{11}$ Using four countries (India, Nepal, Pakistan, and Indonesia) and a variety of methods for evaluating the consistency and external validity of their measures, Filmer and Pritchett assembled substantial evidence to support their claim that the first principal component is a robust proxy measure of living standards. They made creative use of reverse regression methods and techniques akin to instrumental variables to buttress the argument. Perhaps in an excess of enthusiasm, they went so far as to argue that even were consumption expenditures data available, they should be set aside in favor of the principal components proxy.

\section{Factor analysis}

Factor analysis is a method not unlike principal components in that it has mainly been regarded as a means of expressing a set of $k$ observed covariates as a function of a smaller number of common factors. Like principal components, factor analysis focuses on explaining the covariances among the observed variables. The method departs from principal components in two ways: first, the linkages between factors and covariates are specified in a structural model; second, the factors themselves are taken to be unobserved.

\footnotetext{
${ }^{11}$ Filmer and Pritchett viewed consumption expenditures as a proxy measure of long-term socioeconomic status, a view that contrasts with the treatment of Montgomery et al. (2000), in which consumption expenditures were taken to be direct measures of status.
} 
In this approach, the data vector $x_{i}$ (centered to mean zero, with a $k \times k$ variance matrix $V$ as above) is specified as

$$
x_{i}=\Theta f_{i}+\epsilon_{i} .
$$

Here, $f_{i}$ represents a column vector of $m$ unobserved factors for the $i$-th observation, $\Theta$ is a $k \times m$ matrix of factor "loadings," and $\epsilon_{i}$ is a vector of $k$ disturbance terms that is assumed to be uncorrelated with $f_{i}$ and whose covariance matrix $\Omega=E \epsilon_{i} \epsilon_{i}^{\prime}$ is usually taken to be diagonal. In a one-factor model $(m=1)$, the $\Theta$ matrix reduces to a column vector, and the equation for the $j$-th variable in $x_{i}$ can be written as

$$
x_{i, j}=\theta_{j} f_{i}+\epsilon_{i, j}
$$

Letting $\Phi=E f_{i} f_{i}^{\prime}$, the $m \times m$ covariance matrix of the factors, the model implies that

$$
V=E x_{i} x_{i}^{\prime}=\Theta \Phi \Theta^{\prime}+\Omega
$$

is the covariance matrix of the $x_{i}$ covariates. To estimate the unknown parameters on the right-hand side of equation (6), the implied $V$ is compared with its empirical counterpart $\hat{V}$, and parameter values are chosen to minimize the discrepancies between them, using nonlinear least squares or related maximum-likelihood methods.

To compare this specification with its analog in a principal components analysis, we can return to equation (3), which expressed the vector $x_{i}$ as a linear function of all $k$ principal components. Focusing on the $j$-th of the $x_{i}$ variables and writing out that equation in full, we have

$$
x_{i, j}=w_{1, j} p_{i, 1}+w_{2, j} p_{i, 2}+\cdots+w_{2, k} p_{i, k} .
$$

If we then isolate the term associated with the first principal component and group the other terms in a remainder, we can express the result as

$$
x_{i, j}=\delta_{j} p_{i}+u_{i, j}
$$

where $\delta_{j}$ and $p_{i}$ are shorthand for $w_{1, j}$ and $p_{i, 1}$, respectively, and $u_{i, j}$ is a composite remainder somewhat akin to a disturbance term.

Equation (7) bears a superficial resemblance to equation (5). There are, however, two crucial differences. In equation (7) the principal component $p_{i}$ is a directly computable quantity (as are $\delta_{j}$ and $u_{i, j}$ ) whereas the factor $f_{i}$ of equation (5) is unobservable. Furthermore, in a factor-analytic model, the disturbance terms $\left\{\epsilon_{i, j}, j=1, \ldots, k\right\}$ are assumed 
to be mutually uncorrelated. But as Jöreskog (1979: 15) shows, in a principal components approach the remainder terms $\left\{u_{i, j}, j=1, \ldots, k\right\}$ are linked by linear dependencies and therefore cannot be uncorrelated.

Comparison of these methods is further complicated by the need to estimate $f_{i}$, the unobserved factors. Although there exists a variety of estimation methods, the most common is a regression in which an estimated value for $f_{i}$ is computed from a (hypothetical) regression of $f_{i}$ on $x_{i} .{ }^{12}$ As Bollen (1989) points out, one problem is that the estimated factor score $\hat{f}_{i}$ is not itself an error-free measure of $f_{i}$, the true factor. The sampling error in $\hat{f}_{i}$ would not normally affect the consistency of estimators based on $\hat{f}_{i}$, but it would affect their standard errors. Hence, if estimated factor scores are used in a structural model, robust estimates of standard errors must be employed.

\section{Relative Poverty and AcCess to Services}

This section explores the similarities and differences between the principal components score (PCS) and the latent factor score (LFS). Estimation of the principal components model and score is implemented via Stata's factor command; the latent factor model and scores were estimated using the LISREL structural equation modeling software developed by Jöreskog and Sörbom. Our approach is to first standardize each index in terms of percentiles, assigning each household a value that corresponds to its percentile ranking in the distribution of scores. (Standardizations are carried out for urban households only, and are executed separately survey by survey.) We then assess the degree of correlation between the (transformed) PCS and LFS indexes, and examine the relationship between the mean scores and two socioeconomic indicators: the education of the household head and city size. Having satisfied ourselves that the indicators are interpretable as measures of relative living standards, we define urban poor households as those that fall in the lowest quartile of urban PCS or LFS scores, again with reference to

\footnotetext{
${ }^{12}$ See Lawley and Maxwell (1962), Bollen (1989), and Jöreskog (2000). The logic can be seen most easily in the one-factor case. The predicted value of $f_{i}$ from the hypothetical regression of $f$ on $x$ would be

$$
\hat{f}_{i}=x_{i}^{\prime}\left(n^{-1} \sum_{j=1}^{n} x_{j} x_{j}^{\prime}\right)^{-1}\left(n^{-1} \sum_{j=1}^{n} x_{j} f_{j}\right)
$$

For a given $i$, as $n \rightarrow \infty$ the terms in parentheses converge to $V^{-1}$ and $E\left(\Theta f_{j}^{2}+\epsilon_{j} f_{j}\right)=\Theta \sigma_{f}^{2}$, respectively. Estimates of these quantities are available in the estimated covariance matrix of the model; see equation (6). In this paper, we use a new method for estimating $f_{i}$ that is included in the most recent version of LISREL and discussed in depth in Jöreskog (2000).
} 
Table 3 Correlations of latent factor (LF) and principal components (PC) scores, by region

\begin{tabular}{llllll}
\hline $\begin{array}{l}\text { DHS Surveys in } \\
\text { Region }\end{array}$ & $\begin{array}{l}\text { Average } \\
\text { Correlation }\end{array}$ & $\begin{array}{l}\text { Standard De- } \\
\text { viation }\end{array}$ & Minimum & $\begin{array}{l}\text { Maximum } \\
\text { Number } \\
\text { of } \\
\text { Surveys }\end{array}$ \\
\hline North Africa & .95 & .01 & .95 & .96 & 3 \\
Sub-Saharan Africa & .91 & .09 & .61 & .98 & 30 \\
Southeast Asia & .91 & .05 & .86 & .96 & 5 \\
South, Central, & .92 & .05 & .82 & .99 & 10 \\
West Asia & & & & & \\
Latin America & .95 & .03 & .90 & .98 & 13 \\
All countries & .92 & .07 & .61 & .99 & 61 \\
\hline
\end{tabular}

the distribution of scores produced by a given survey. By construction, therefore, these measures of poverty are relative. Finally, the relative poverty measures are entered into multivariate probit regressions in which the dependent variables are indicators of access to services. These regressions include measures of city size and education, so that the net effects of relative poverty can be isolated.

\section{Descriptive results}

Table 3 summarizes the correlations between the normalized principal components (PC) and latent factor (LF) scores. The correlations are summarized in terms of averages by region and also for all countries in the analysis. Evidently, in spite of their dissimilar theoretical origins, the normalized principal components and latent factor scores are empirically very closely associated. The average correlation between the two measures is no less than 0.92. In the surveys from Latin America and North Africa, this correlation never falls below 0.90 and for some countries it achieves levels near unity. Indeed, the correlation coefficient drops below 0.80 only for two countries in the full sample, Namibia (1992) and Rwanda (1992).

Table 4 explores these associations further. It is derived from a bivariate table in which households are ranked by their quartile in each score, and the off-diagonal cells are inspected to see how often households fall into different quartiles. Again, it seems that little separates the two living standards measures. Only 10.7 percent of the households are found in a different quartile in the PCS distribution than they would occupy in the LFS distribution. Focusing on the lowest quartile, which will be used subsequently to 
Table 4 Differences in household rankings obtained from the latent factor (LF) and principal components (PC) score distributions, by region

\begin{tabular}{lllll}
\hline $\begin{array}{l}\text { DHS Surveys in } \\
\text { Region }\end{array}$ & $\begin{array}{l}\text { Change in } \\
\text { Any Quartile }\end{array}$ & $\begin{array}{l}\text { Lowest PC } \\
\text { Quartile to } \\
\text { Higher LF } \\
\text { Quartile }\end{array}$ & $\begin{array}{l}\text { Higher LF } \\
\text { Quartile to } \\
\text { Lowest PC } \\
\text { Quartile }\end{array}$ & $\begin{array}{l}\text { Any Change in } \\
\text { Lowest Quartile }\end{array}$ \\
\hline North Africa & 6.2 & 2.9 & 2.5 & 5.4 \\
Sub-Saharan Africa & 8.1 & 1.4 & 1.3 & 2.7 \\
Southeast Asia & 7.0 & 1.0 & 1.2 & 1.9 \\
South, Central, & 17.9 & 3.0 & 3.8 & 6.8 \\
West Asia & & & & \\
Latin America & 13.4 & 2.2 & 2.4 & 4.6 \\
All countries & 10.7 & 1.9 & 2.0 & 3.9 \\
\hline
\end{tabular}

designate the urban poor, we find that only 3.9 percent of households located in this quartile by one measure are placed in a different quartile by the other.

Still more evidence of the similarities in the PCS and LFS is seen in the differences in their mean values given city size and education of the household head. Figure 4 depicts the average percentiles of the PC and LF scores by city size. This figure depicts modest increases in the average living standards index with city size, and the two measures of living standards behave all but identically. Likewise, when a similar graph is produced according to the education of the household head (Figure 5), the results show that education is positively associated with living standards and that differences in the two measures are almost imperceptible. The rise in living standards with education is clearly more pronounced than in the case of city size.

To further illustrate the relationship between living standards, city size, and education, the latent factor score was used to generate a three-way plot involving all of these measures. The results are presented in Figure 6 for Latin America (very similar graphs, not shown, are obtained for the other regions). The most advantaged position in terms of relative living standards is achieved by households whose heads have more than secondary schooling and who live in the largest cities. The least advantaged position is occupied by households whose heads have no schooling and who live in the smallest cities. In the small cities, average living standards increase by 40 points (percentiles) from the least to the most educated groups, whereas increases of only 30 percentiles are seen in the largest 
Figure 4 Relative living standards indexes by city size
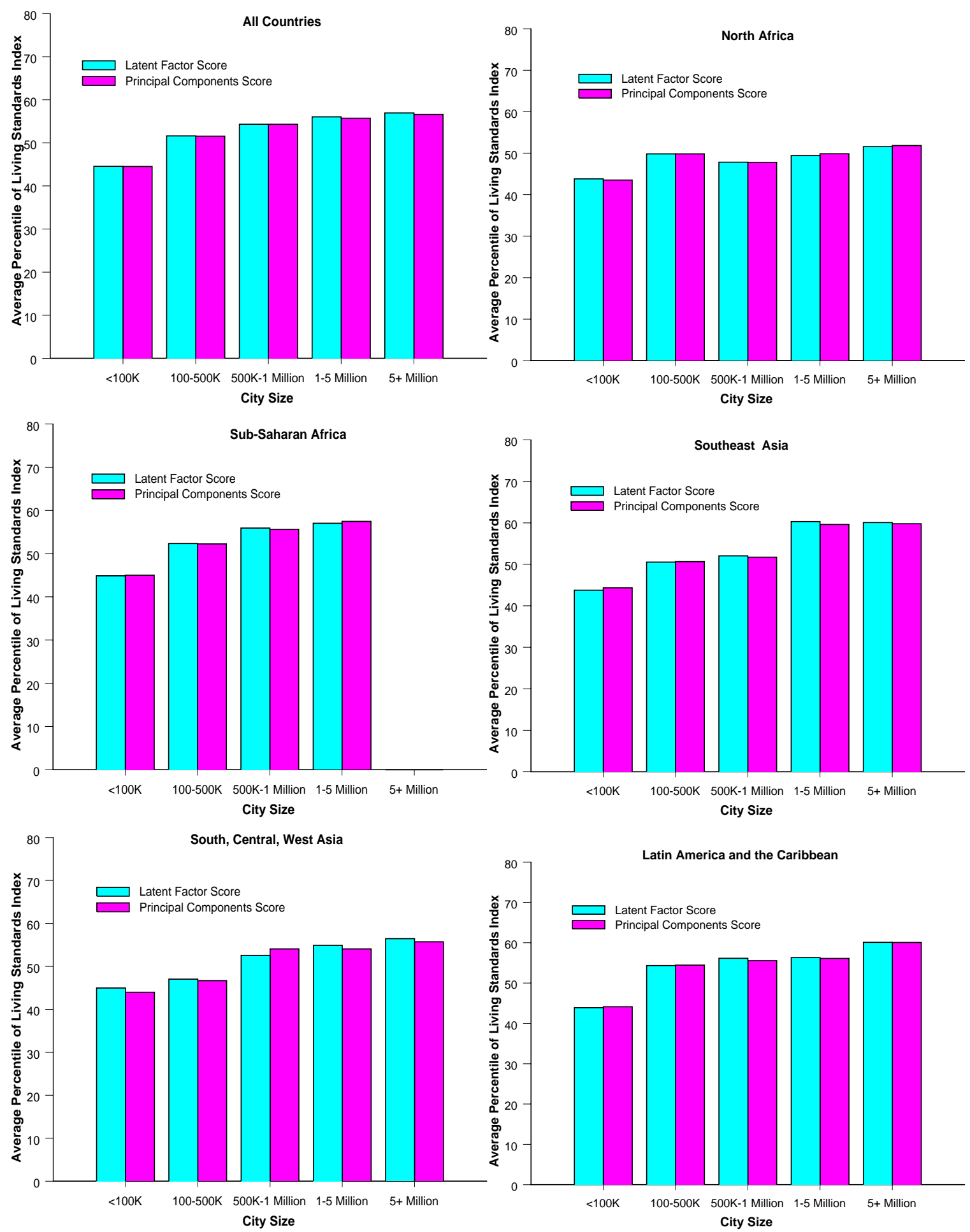
Figure 5 Relative living standards indexes by education of the household head
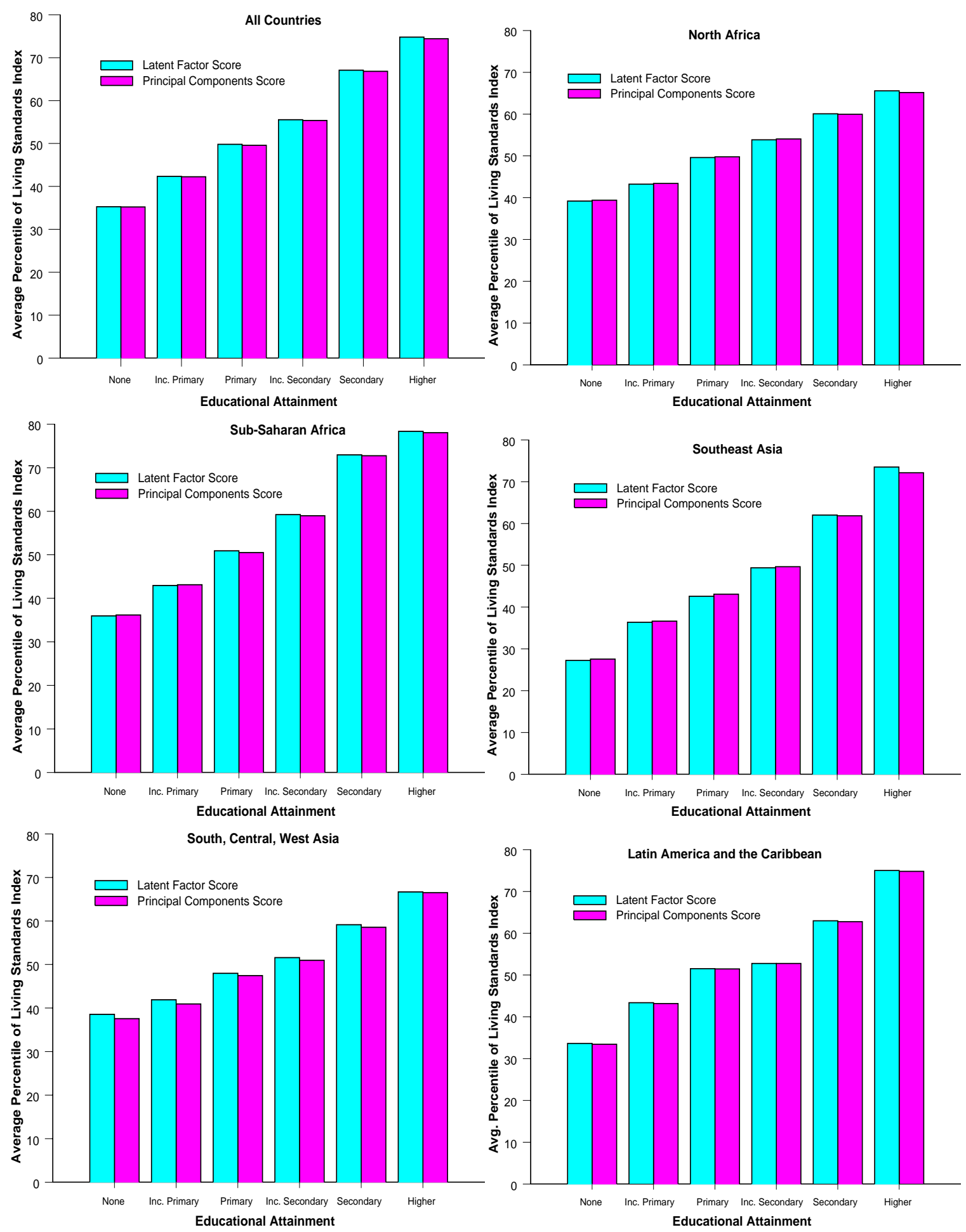
Figure 6 Relative living standards index by city size and education, Latin America

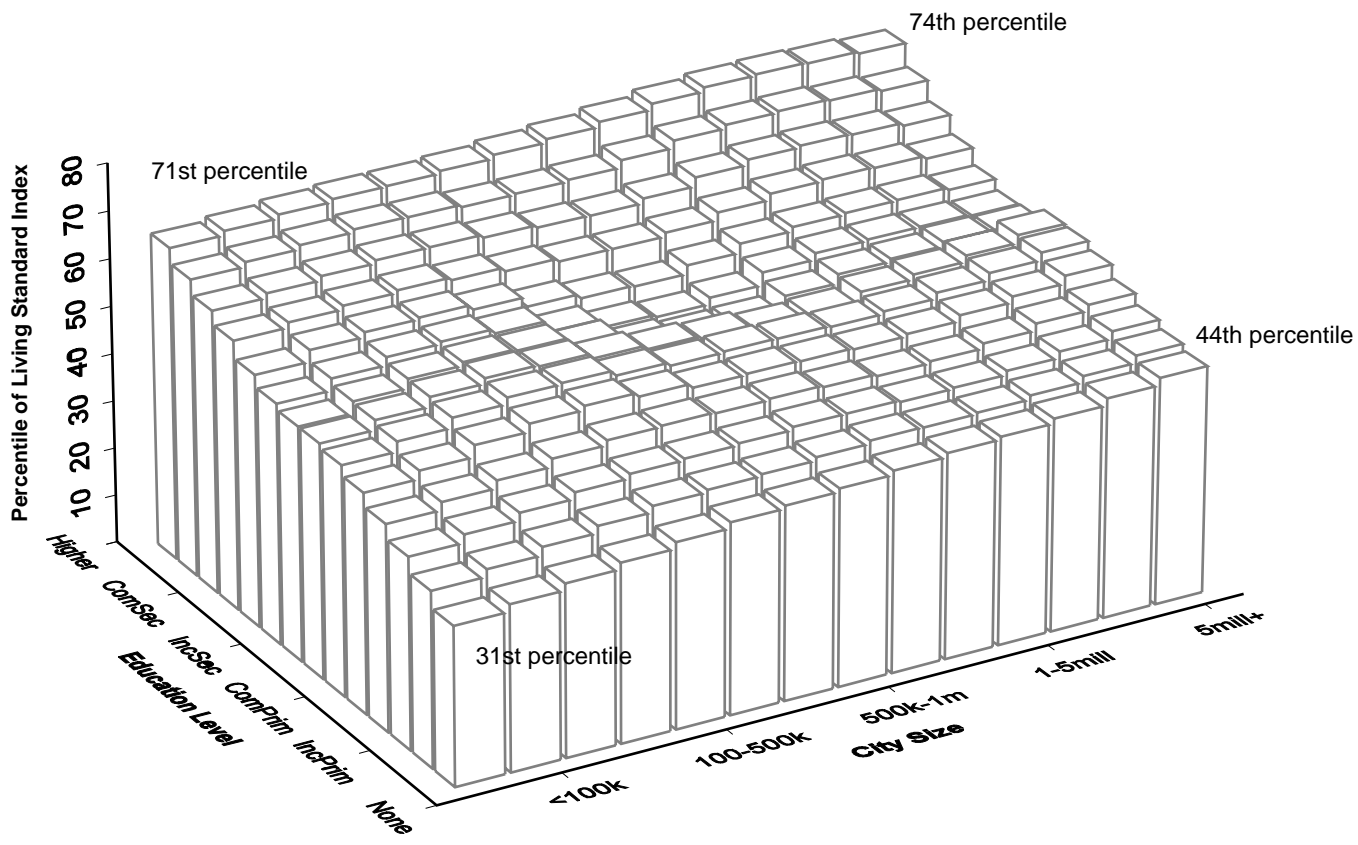

cities. These results suggest why less educated urban-to-urban migrants might find the largest cities attractive. ${ }^{13}$

\section{Multivariate results}

Our multivariate analysis returns to the question of access to public services. As before, we concentrate attention on three services-piped water in the residence, access to flush toilets, and the availability of electricity-and complement these with a fourth measure of disadvantage, indicating whether the household lacks access to all three services. Interest centers on the role played by relative poverty, city size, and educational attainment of the household head. The results presented above uncovered very little by way of empirical difference between the principal components and factor score measures, and we have reconfirmed their similarities in multivariate models. Hence, we will present here only the results based on the factor scores.

The estimates are based on a probit regression model that can be expressed as:

$$
P(Y=1 \mid \hat{f}, c, e)=\Phi\left(\hat{f}^{\prime} \beta_{f}+c^{\prime} \beta_{u}+e^{\prime} \beta_{e}\right)
$$

\footnotetext{
${ }^{13}$ As shown in Montgomery et al. (2001), roughly 2 out of every 3 recent migrants to urban areas have urban origins. This figure is based on an analysis of DHS individual surveys of women, who are defined to be recent migrants if they have moved within the 5 years leading up to the survey.
} 


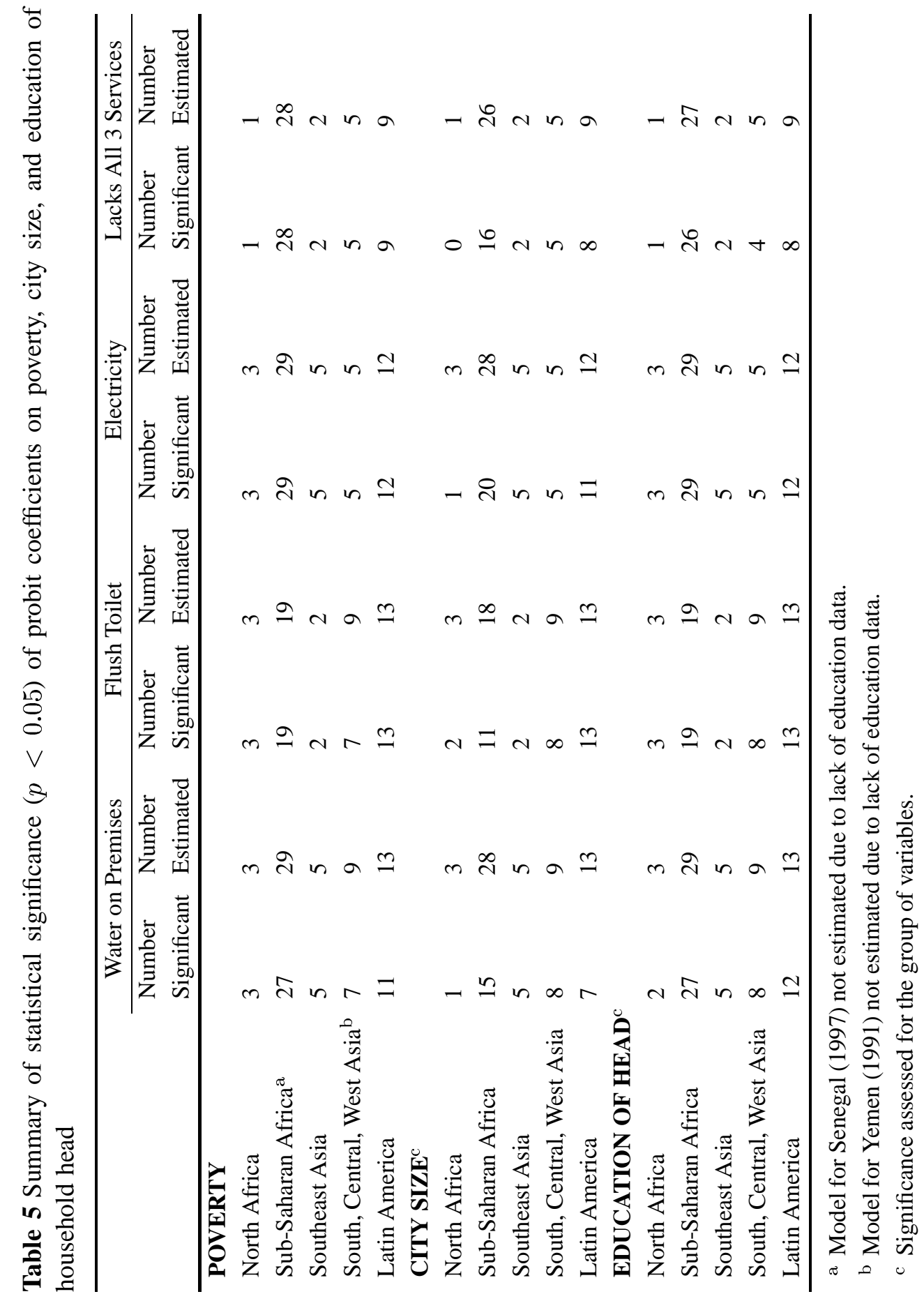


where $\Phi$ is the standard normal distribution function, $\hat{f}$ is the estimated factor score, $c$ is the set of city size variables, and $e$ represents the educational attainment of the household head. Appendix Table A.2 presents the estimated coefficients, robust standard errors, and significance levels on a survey-by-survey basis. Table 5 summarizes the results in terms of statistical significance. Relative poverty is seen to be a highly significant influence on access to services: the factor score is statistically insignificant in only eight (4 percent) of the regressions estimated. The multivariate results for city size and education are also strong. Chi-square tests reject the hypothesis that city size has no effect in 73 percent of the estimated models; for the education variables, the hypothesis is rejected in 96 percent of the models. As can be seen Table 5, these results are consistent across the regions. ${ }^{14}$ In sum, the multivariate results clearly indicate that relative poverty greatly reduces access to services, while both living in larger cities and higher levels of education translate into greater access to services.

To highlight the poverty comparisons, these results are summarized in terms of predicted probabilities of access in Table 6 . There are striking differences in access to services between the urban poor households and those that are not poor according to our relative definition of poverty. The largest differences emerge in access to electricity, which in sub-Saharan African countries is available to only a quarter of the urban poor but to more than half of non-poor urban households. Wide differentials in access are also evident in Southeast Asia and South, Central, and West Asia. In Latin America, the greatest differences between the urban poor and non-poor are seen in access to flush toilets, with smaller (yet still significant) differentials in piped water and electricity.

Table 7 depicts the education effects in terms of predicted probabilities of access. In the urban areas of sub-Saharan Africa, 1 of every 2 households whose head has no education lacks access to all three public services. But where the household heads have secondary schooling, only 1 in 5 households is similarly disadvantaged, and among heads with higher schooling, the ratio falls to 1 in 10 . Also, as might have been expected, the inequalities in access to services across educational groups are greatest in sub-Saharan

\footnotetext{
${ }^{14}$ An examination of the individual regression coefficients for city size and education (see Table A.2) reveals similar patterns. Considering whether the estimated coefficients are both statistically significant and in the expected direction (positive for both city size and education), we obtain the following results by type of service. For water on the premises, 36 percent of the city size estimates are significant and positive, as are 57 percent of the education coefficients; for flush toilets, the percentages are 58 percent and 73 percent, respectively; for electricity, 64 percent and 74 percent; and for lacking all three services, 52 percent and 70 percent.
} 
Table 6 Predicted percentages of households with access to services by relative poverty status $^{\text {a }}$

\begin{tabular}{lllll}
\hline DHS Countries in Region & $\begin{array}{l}\text { Water on } \\
\text { Premises }\end{array}$ & Flush Toilet & Electricity & $\begin{array}{l}\text { Lacks All 3 } \\
\text { Services }\end{array}$ \\
\hline North Africa & & & & \\
Urban Poor & .75 & .88 & .86 & .08 \\
Urban Non-Poor & .92 & .97 & .97 & .02 \\
Sub-Saharan Africa & & & & \\
Urban Poor & .31 & .20 & .26 & .57 \\
Urban Non-Poor & .46 & .32 & .52 & .34 \\
Southeast Asia & & & & \\
Urban Poor & .36 & .67 & .77 & .12 \\
Urban Non-Poor & .50 & .88 & .97 & .01 \\
South, Central, West Asia & & & & .22 \\
Urban Poor & .59 & .48 & .71 & .06 \\
Urban Non-Poor & .74 & .60 & .92 & .12 \\
Latin America & & & & .02 \\
Urban Poor & .59 & .44 & .84 & .98 \\
Urban Non-Poor & .74 & .67 &
\end{tabular}

a Poverty is measured by a latent factor score, and defined as falling within the lowest quartile of the urban distribution of scores for a given survey.

Africa, with much wider disparities between those with little or no education and those with higher levels of educational attainment.

\section{CONCLUSIONS}

We offer two types of conclusions: those having to do with methods and those pertaining to substance. Where methods are concerned, we have found little difference in the empirical performance of indexes based on confirmatory factor analysis and those based on a principal components approach. With regard to substance, we have found sharp inequalities in access to public services between the urban poor and other urban residents, and between the educated and the less-educated. These differences are sufficiently robust to emerge in multivariate as well as bivariate analyses. We have also uncovered clear evidence that smaller cities are less well-served than larger cities. Although sometimes large, these intra-urban differences pale by comparison to urban-rural differences in access, which can be enormous. 
Table 7 Predicted percentages of households with access to services by education of head, controlling for city size and relative poverty

\begin{tabular}{|c|c|c|c|c|}
\hline DHS Surveys in Region & $\begin{array}{l}\text { Water on } \\
\text { Premises }\end{array}$ & Flush Toilet & Electricity & $\begin{array}{l}\text { Lacks All } 3 \\
\text { Services }\end{array}$ \\
\hline \multicolumn{5}{|l|}{ North Africa } \\
\hline No Schooling & .84 & .91 & .92 & .05 \\
\hline Incomplete Primary & .85 & .95 & .94 & .03 \\
\hline Primary & .86 & .94 & .95 & .03 \\
\hline Incomplete Secondary & .90 & .96 & .97 & .02 \\
\hline Secondary & .94 & .98 & .99 & .00 \\
\hline Higher & .96 & .99 & .99 & .01 \\
\hline \multicolumn{5}{|l|}{ Sub-Saharan Africa } \\
\hline No Schooling & .33 & .20 & .33 & .51 \\
\hline Incomplete Primary & .35 & .22 & .36 & .48 \\
\hline Primary & .39 & .23 & .42 & .43 \\
\hline Incomplete Secondary & .46 & .31 & .54 & .32 \\
\hline Secondary & .61 & .45 & .70 & .19 \\
\hline Higher & .70 & .61 & .79 & .13 \\
\hline \multicolumn{5}{|l|}{ Southeast Asia } \\
\hline No Schooling & .26 & .51 & .83 & .17 \\
\hline Incomplete Primary & .31 & .62 & .86 & .11 \\
\hline Primary & .40 & .78 & .89 & .05 \\
\hline Incomplete Secondary & .46 & .82 & .91 & .03 \\
\hline Secondary & .48 & .79 & .93 & .05 \\
\hline Higher & .57 & .86 & .96 & .02 \\
\hline \multicolumn{5}{|c|}{ South, Central, West Asia } \\
\hline No Schooling & .49 & .42 & .74 & .21 \\
\hline Incomplete Primary & .51 & .48 & .79 & .15 \\
\hline Primary & .65 & .52 & .82 & .14 \\
\hline Incomplete Secondary & .69 & .56 & .87 & .09 \\
\hline Secondary & .72 & .61 & .90 & .06 \\
\hline Higher & .77 & .72 & .90 & .06 \\
\hline \multicolumn{5}{|l|}{ Latin America } \\
\hline No Schooling & .67 & .51 & .90 & .06 \\
\hline Incomplete Primary & .68 & .54 & .92 & .05 \\
\hline Primary & .70 & .59 & .93 & .04 \\
\hline Incomplete Secondary & .70 & .60 & .95 & .03 \\
\hline Secondary & .71 & .68 & .96 & .03 \\
\hline Higher & .74 & .79 & .97 & .03 \\
\hline
\end{tabular}


On the methodological front, a good deal of investigation remains before any statistical approach can be declared superior. The next phase of research should examine structural models in which the factor scores $f$ are estimated jointly with the structural equation in which they are entered. We urge consideration of specifications such as

$$
\begin{aligned}
Y & =X^{\prime} \beta+f+u \\
X_{1} & =f \Theta_{1}+\epsilon_{1} \\
& \vdots \\
X_{k} & =f \Theta_{k}+\epsilon_{k}
\end{aligned}
$$

in which $Y$ is the outcome of structural interest, $f$ is the unobserved factor (which might be multi-dimensional), and additional equations link covariates $X_{1}, \ldots, X_{k}$ to this factor. (The remaining terms, $u$ and $\epsilon_{1}, \ldots, \epsilon_{k}$, are the structural and factor disturbance terms.) A model such as this imposes more discipline on the estimation of the factor loadings $\Theta$ than does confirmatory factor analysis, in which the $\Theta$ are estimated without any reference to the structural equation. Hence, provided that the assumptions underlying the equation system are valid, this joint estimation approach provides much stronger grounds for conclusions about the effects of living standards. Bollen (1989) gives a good account of the differences between confirmatory and structural factor-analytic approaches, which he and colleagues are exploring in research based on Living Standards Measurement Survey data. The equation system represents the kind of extension that is a natural generalization of confirmatory factor analysis, and that has no counterpart in the case of principal components.

Returning to the substantive findings and their implications for policy, we should consider how the gaps in public service provision might be closed, so that the urban poor and residents of smaller cities obtain the same access as do the non-poor and residents of large cities. Because public services are subject to scale and scope economies, their provision must usually be arranged by governments. Of late, however, the question of which governments are to take responsibility has been thrown into confusion.

At the outset we mentioned that national governments in many developing countries are decentralizing many of their responsibilities to lower-tier governments, such as those at the state, district, metropolitan, and local levels. The case of Accra, Ghana, is instructive. Ghana has formally decentralized many national government functions to its 110 district assemblies, which among other things are to provide for the delivery of pub- 
lic services in their local areas, using transfers from the national government and newly endowed powers of revenue-raising. But the decentralization of authority has not yet been matched by sufficient central government transfers, and the assemblies often lack the managerial expertise to carry out the functions allotted to them. Even within the Greater Accra Metropolitan Area, according to Gough and Yankson (2001), the district assemblies simply lack the means to provide services. Local community-based and nongovernmental organizations (NGOs) are stepping forward in an effort to close the gap in service delivery.

In central Accra, an NGO in the Muslim-dominated, low-income settlement of Nima has received funds from the Nation of Islam (the U.S. group) to confront the problem of poor local sanitation. Their effort is led by a local chief and coordinated partly through neighborhood mosques, which provide meeting places and sources of information about the clean-up efforts. By all accounts, this local NGO is succeeding where local governments had long failed. Although the NGO has ambitions to move beyond waste collection into other public services, it may lack the technical resources to do so. Nevertheless, the record is encouraging so far as it goes.

By contrast, in the relatively high-income settlement of East Legon, the district assembly and the Ghana Water and Sewage Authority have refused to provide further funds for water supply connections. Residents have been forced to form their own associations to gather the funds and labor needed to connect their homes to the main pipes. Part of the problem lies in the nature of local civil society - the chief who controls land in East Legon lives elsewhere, and is evidently disinclined to exert political influence on behalf of the residents. In the outlying settlement of Gbawe, however, the local chiefs have access to funds raised by the sale of leaseholds on local land (which chiefs control by custom) and have made use of them for a variety of local infrastructural investments, including the provision of public toilets, piped water, and clearing of access roads. The chiefs and elders of this settlement are greatly aided in their efforts by the good relations they enjoy with the district assemblymen.

These are examples in which elements of the local civil society, faced with unresponsive or underfunded local governments, are taking up responsibility for investments in public service provision. It is not clear whether such small groups can effectively substitute for active governments. The organizational and transaction costs borne by local groups can be considerable-in the case of East Legon, the residents' association must 
deal with numerous free-rider problems and somehow enforce payment of the association dues and fees. Nor is it a given that local groups are any more transparent and accountable in their operations than governments. In other parts of Ghana, according to Gough and Yankson (2001), the local chiefs have been known to make off with the proceeds of land sales, and corruption siphons the funds that could have extended services.

Similar accounts in which local groups attempt to step in for governments to provide services have been given for urban housing cooperatives in Zimbabwe (Kamete 2001), associations of landowners in the Democratic Republic of Congo and community associations collecting solid wastes in Yaoundé (Tati 2001), and solid waste collection in Cairo (Myllylä 2001) and Dar es Salaam (Mhamba and Titus 2001). A recent issue of the journal Environment and Urbanization reviews the roles of slum dweller federations in securing access to housing and services, citing cases from India, Cambodia, Thailand, the Philippines, Namibia, Zimbabwe, and South Africa. ${ }^{15}$ Across much of the developing world, such partnerships linking community groups to local and national NGOs are attracting considerable attention, as shown in the comprehensive review (as of the mid-1990s) given in UNCHS (1996: Chapter 11).

As developing-country governments decentralize, the questions of what goverments are responsible for service provision, and how best to bring political pressure to bear on key policymakers, will probably become increasingly complex. In decentralized political systems, it can be expected that both governments and local associations will attempt to slough off responsibilities onto other groups; and until the situation is sorted out, gross inefficiencies and gaps will probably continue to plague the provision of public services. It may be that in such governmental systems, no one tier of government is charged with ensuring that public services are equitably provided.

\section{REFERENCES}

Bollen, Kenneth. 1989. Structural Equations with Latent Variables, New York: John Wiley \& Sons.

Brockerhoff, Martin. 1990. "Rural to urban migration and child survival in Senegal," Demography 27(4): 601-16.

\footnotetext{
${ }^{15}$ See Environment and Urbanization, volume 13, number 2 (2001), for these case studies.
} 
Brockerhoff, Martin and Paul C. Hewett. 2000. "Inequality in child mortality in subSaharan Africa," Bulletin of the World Health Organization 78(1): 30-41.

Davis, Jennifer, Alice Kang, and Jeffrey Vincent. 2001. "How important is improved water infrastructure to microenterprises? Evidence from Uganda," World Development 29(10): 1753-67.

Deaton, Angus. 2001. "Counting the world's poor: Problems and possible solutions," The World Bank Research Observer 16(2): 125-48.

Dunteman, George H. 1989. Principal Components Analysis, vol. 69 of Quantitative Applications in the Social Sciences, Newbury Park, CA: Sage Publications.

Filmer, Deon and Lant Pritchett. 1999. "The effect of household wealth on educational attainment: Evidence from 35 countries," Population and Development Review 25(1): 85-120.

—. 2001. "Estimating wealth effects without expenditure data—or tears: An application to educational enrollments in states of India," Demography 38(1): 115-32.

Gough, Katherine V. and Paul W. K. Yankson. 2001. "The role of civil society in urban management," in Arne Tostensen, Inge Tvedten, and Mariken Vaa (eds.), Associational Life in African Cities: Popular Responses to the Urban Crisis, pages 127-43, Uppsala, Sweden: Nordiska Afrikainstitutet.

Johansson, S. Ryan and Carl Mosk. 1987. "Exposure, resistance and life expectancy: Disease and death during the economic development of Japan, 1900-1960," Рориlation Studies 41(2): 207-35.

Jöreskog, Karl G. 1979. "Basic ideas of factor and component analysis," in Karl G. Jöreskog and Dag Sörbom (eds.), Factor Analysis and Structural Equation Models, pages 5-20, Cambridge, MA: ABT Books.

—. 2000. "Latent variable scores and their uses," unpublished paper, available at http://www.ssicentral.com/lisrel.column6.pdf.

Kamete, Amin Y. 2001. "Civil society, housing and urban governance: The case of urban housing co-operatives in Zimbabwe," in Arne Tostensen, Inge Tvedten, and Mariken Vaa (eds.), Associational Life in African Cities: Popular Responses to the Urban Crisis, pages 162-79, Uppsala, Sweden: Nordiska Afrikainstitutet. 
Lawley, D. N. and A. E. Maxwell. 1962. "Factor analysis as a statistical method," Statistician 12(3): 209-29.

Manor, James. 1999. The Political Economy of Democratic Decentralization, Washington, DC: The World Bank.

Mhamba, Robert M. and Colman Titus. 2001. "Reactions to deteriorating provision of public services in Dar es Salaam," in Arne Tostensen, Inge Tvedten, and Mariken Vaa (eds.), Associational Life in African Cities: Popular Responses to the Urban Crisis, pages 218-31, Uppsala, Sweden: Nordiska Afrikainstitutet.

Montgomery, Mark R. 1987. "The impacts of urban population growth on urban labor markets and the costs of urban service delivery," in D. Gale Johnson and Ronald D. Lee (eds.), Population Growth and Economic Development: Issues and Evidence, Madison, WI: University of Wisconsin Press.

-. 1988. "How large is too large? Implications of the city size literature for population policy and research," Economic Development and Cultural Change 36(4): 691720.

Montgomery, Mark R., Michele Gragnolati, Kathleen A. Burke, and Edmundo Paredes. 2000. "Measuring living standards with proxy variables," Demography 37(2): $155-74$.

Montgomery, Mark R., Paul Hewett, and Brian Pence. 2001. "Results from the Demographic and Health Surveys: A guidebook," unpublished paper prepared for the Panel on Urban Population Dynamics, Committee on Population, National Research Council.

Myllylä, Susanna. 2001. "NGOs in urban environmental governance: Waste recycling in Cairo," in Arne Tostensen, Inge Tvedten, and Mariken Vaa (eds.), Associational Life in African Cities: Popular Responses to the Urban Crisis, pages 198-217, Uppsala, Sweden: Nordiska Afrikainstitutet.

Preston, Samuel H. and Etienne van de Walle. 1978. "Urban French mortality in the nineteenth century," Population Studies 32(2): 275-97.

Sahn, David E. and David C. Stifel. 2000. "Poverty comparisons over time and across countries in Africa," World Development 28(12): 2123-55. 
Schott, James R. 1997. Matrix Analysis for Statistics, New York: John Wiley and Sons.

Tati, Gabriel. 2001. "Responses to the urban crisis in Cameroon and Congo: Patterns of local participation in urban management," in Arne Tostensen, Inge Tvedten, and Mariken Vaa (eds.), Associational Life in African Cities: Popular Responses to the Urban Crisis, pages 182-97, Uppsala, Sweden: Nordiska Afrikainstitutet.

UNCHS. 1996. An Urbanizing World: Global Report on Human Settlements 1996, Oxford and New York: Oxford University Press for the United Nations Centre on Human Settlements (Habitat).

United Nations. 2000. World Urbanization Prospects: The 1999 Revision: Data Tables and Highlights, New York: United Nations, Department of Economic and Social Affairs, Population Division.

Van Poppel, Frans and Cor van der Heijden. 1997. "The effects of water supply on infant and child mortality: A review of historical evidence," Health Transition Review 7: $113-48$.

World Bank. 1994. World Development Report 1994: Infrastructure for Development, New York: Oxford University Press. 


\section{APPENDix}

Table A.1 Demographic and Health Surveys, Phases II and III

\begin{tabular}{llll}
\hline Country & Survey Year & Country & Survey Year \\
\hline North Africa & & Southeast Asia & \\
Egypt & 1992,1995 & Indonesia & $1991,1994,1997$ \\
Morocco & 1992 & Philippines & 1993,1998 \\
Sub-Saharan Africa & & South, Central, West Asia & \\
Benin & 1996 & Bangladesh & $1993-94,1996-97$ \\
Burkina Faso & 1993 & India & 1992 \\
Cameroon & 1991,1998 & Kazakhstan & 1995 \\
Central African Republic & $1994-95$ & Kyrgyzstan & 1997 \\
Chad & $1996-97$ & Nepal & 1996 \\
Comoros & 1996 & Pakistan & $1990-91$ \\
Côte d'Ivoire & 1994 & Turkey & 1993 \\
Ghana & $1993,1998-99$ & Uzbekistan & 1996 \\
Kenya & 1993,1998 & Yemen & 1991 \\
Madagascar & 1992,1997 & Latin America & \\
Malawi & 1992 & Bolivia & 1994,1998 \\
Mali & $1995-96$ & Brazil & 1996 \\
Mozambique & 1997 & Colombia & 1990,1995 \\
Namibia & 1992 & Dominican Republic & 1991,1996 \\
Niger & 1992,1998 & Guatemala & 1995,1999 \\
Rwanda & 1992 & Haiti & $1994-95$ \\
Senegal & $1992-93,1997$ & Nicaragua & 1998 \\
Tanzania & $1991-92,1996$ & Peru & $1991-92,1996$ \\
Togo & 1998 & & \\
Uganda & 1995 & & \\
Zambia & 1992,1996 & & \\
Zimbabwe & 1994 & & \\
\hline
\end{tabular}




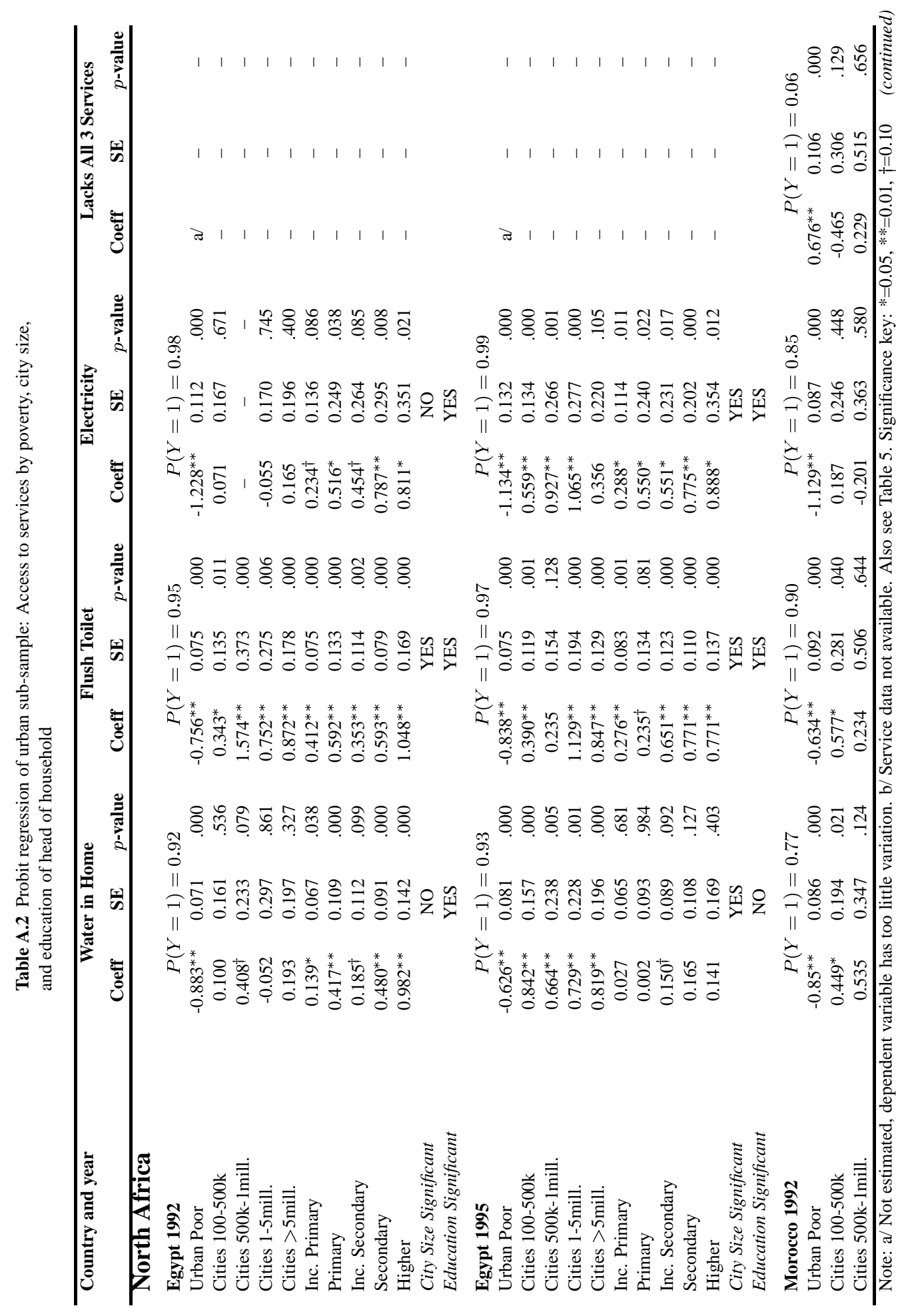




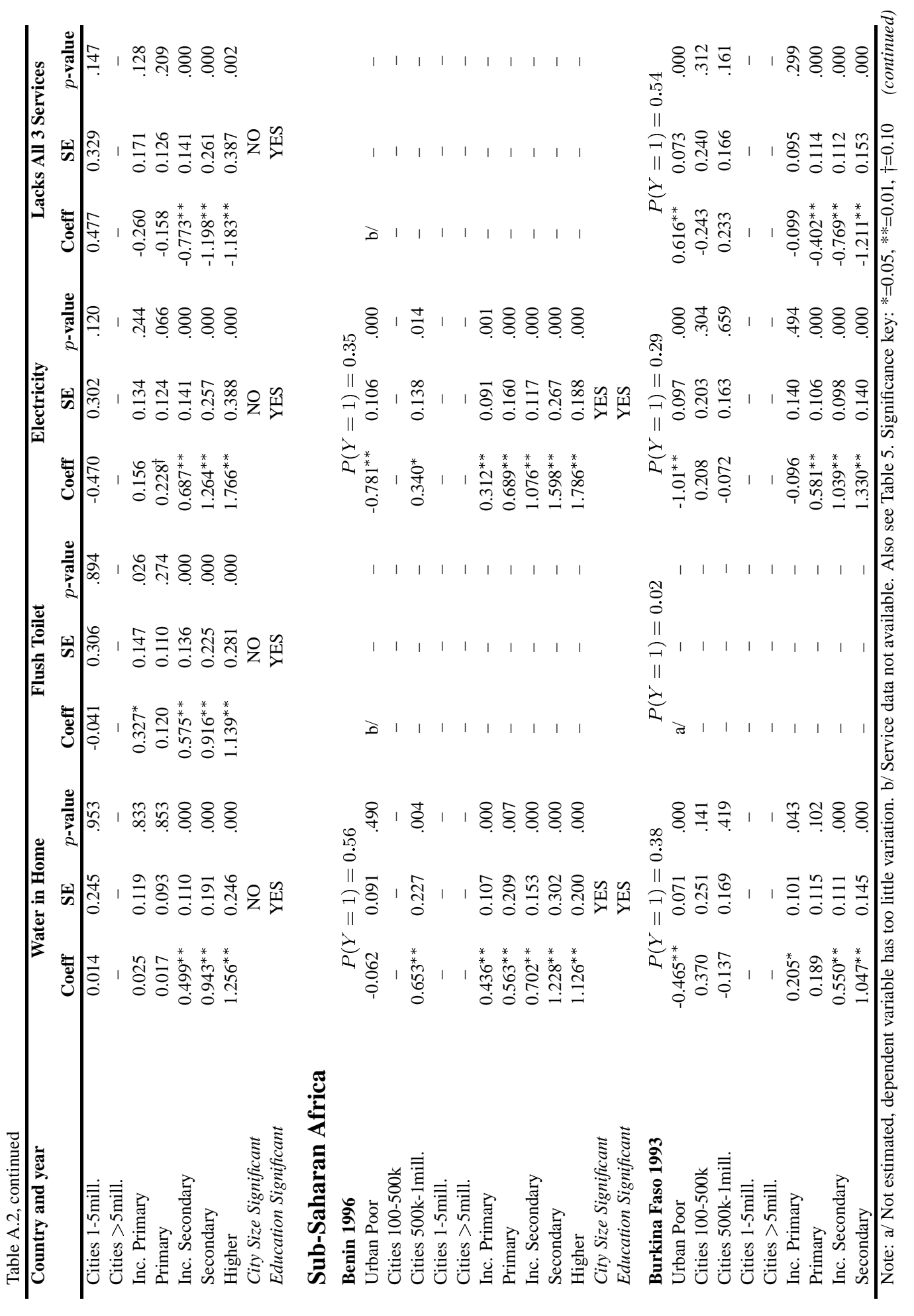




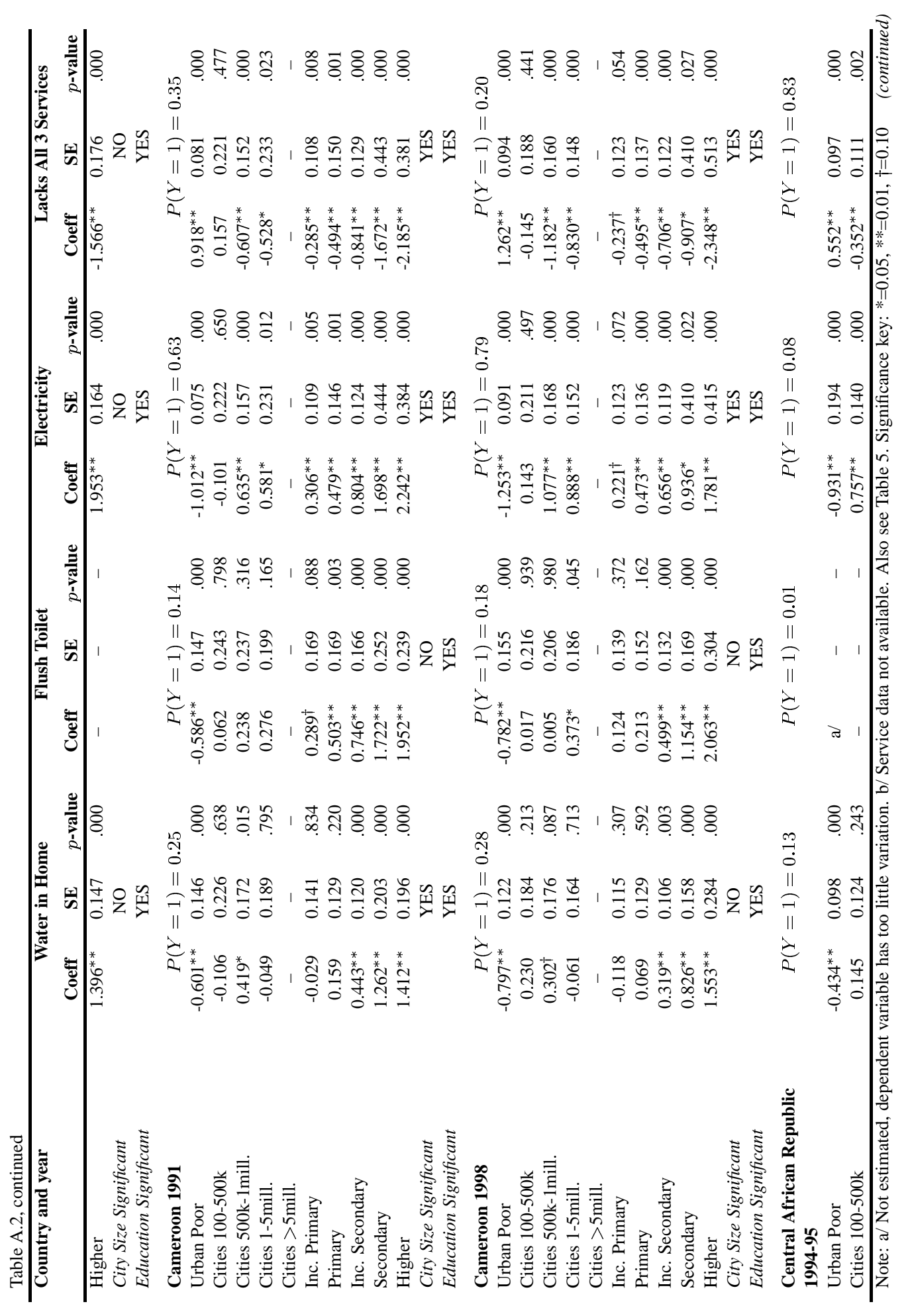




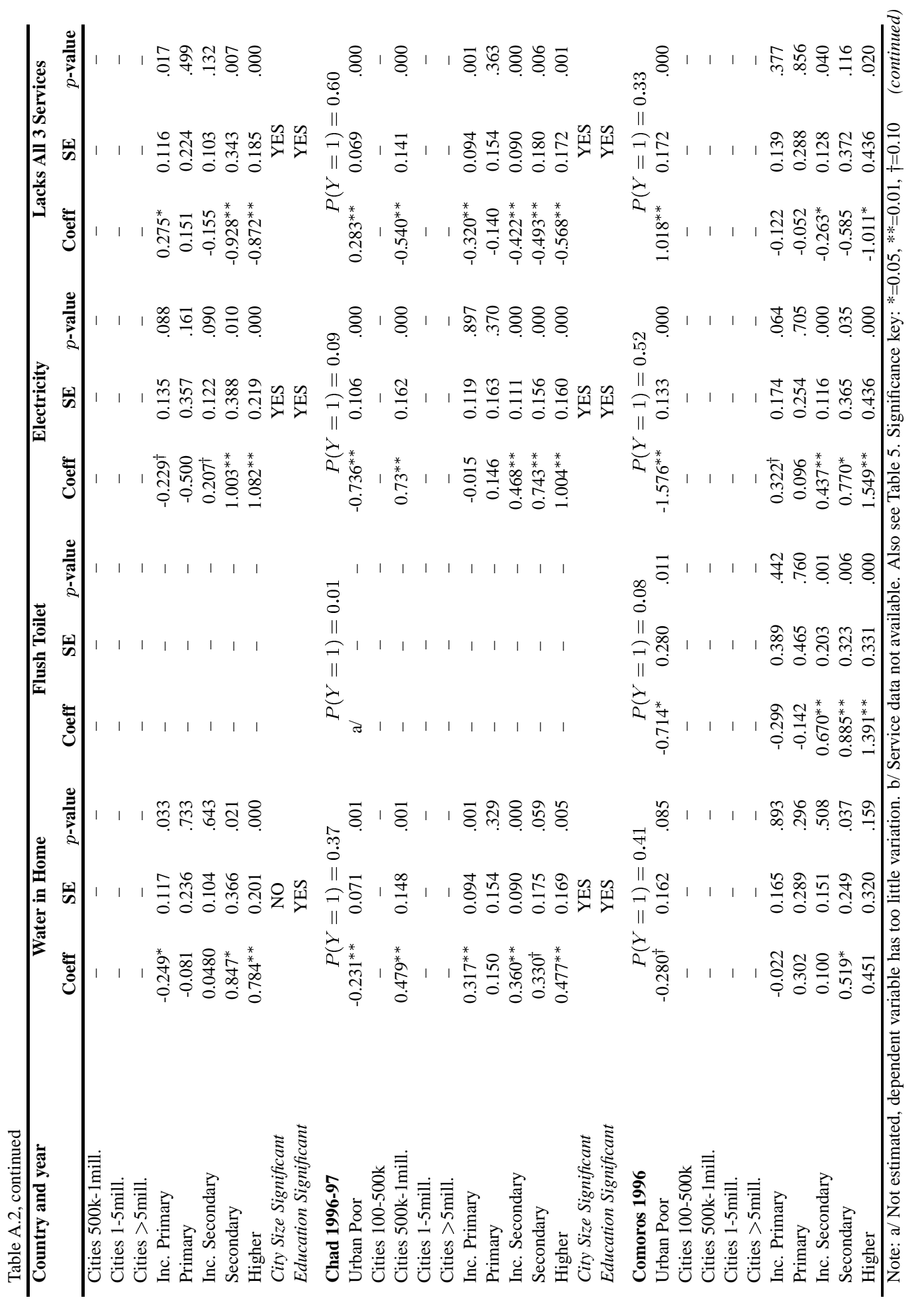




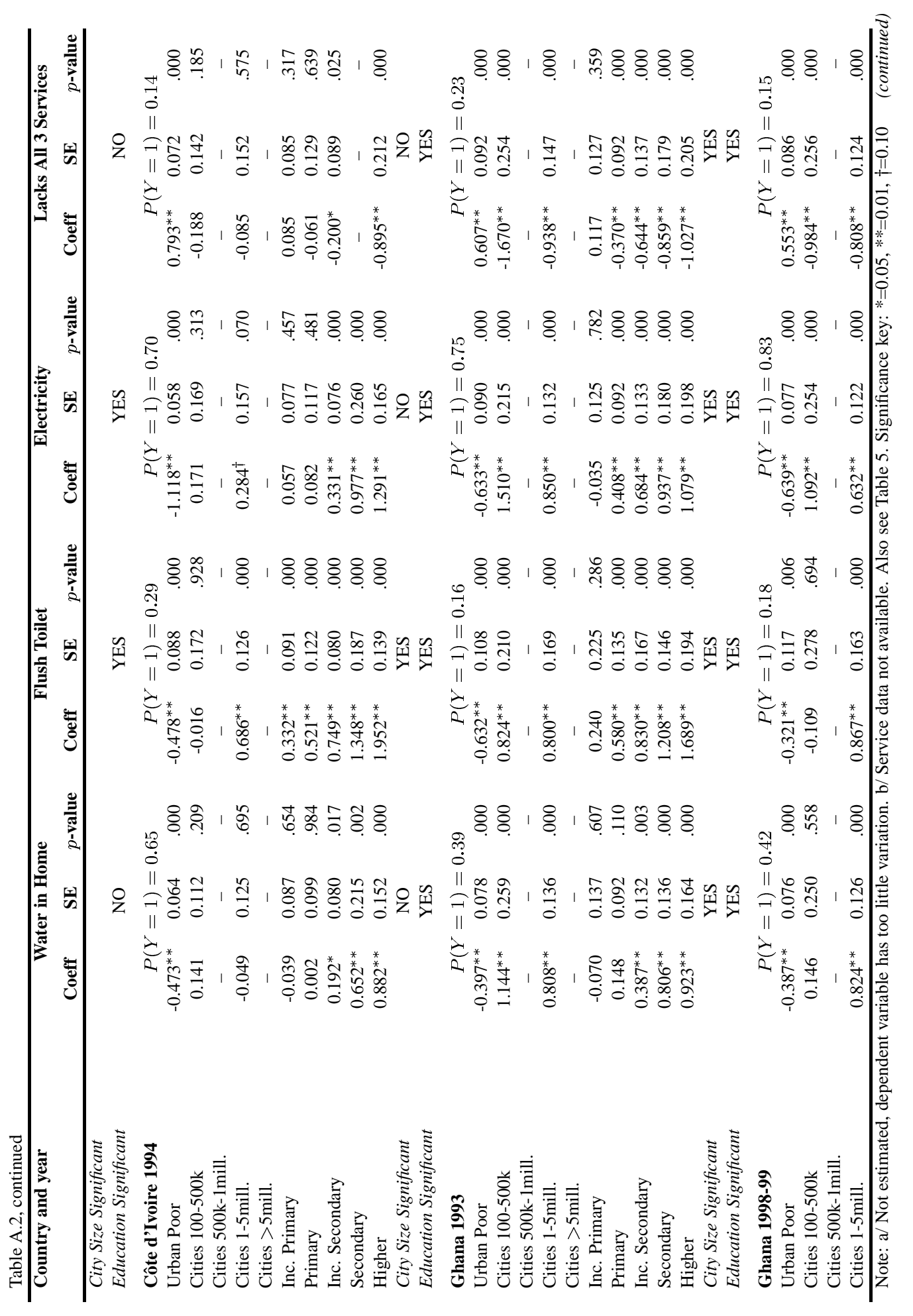




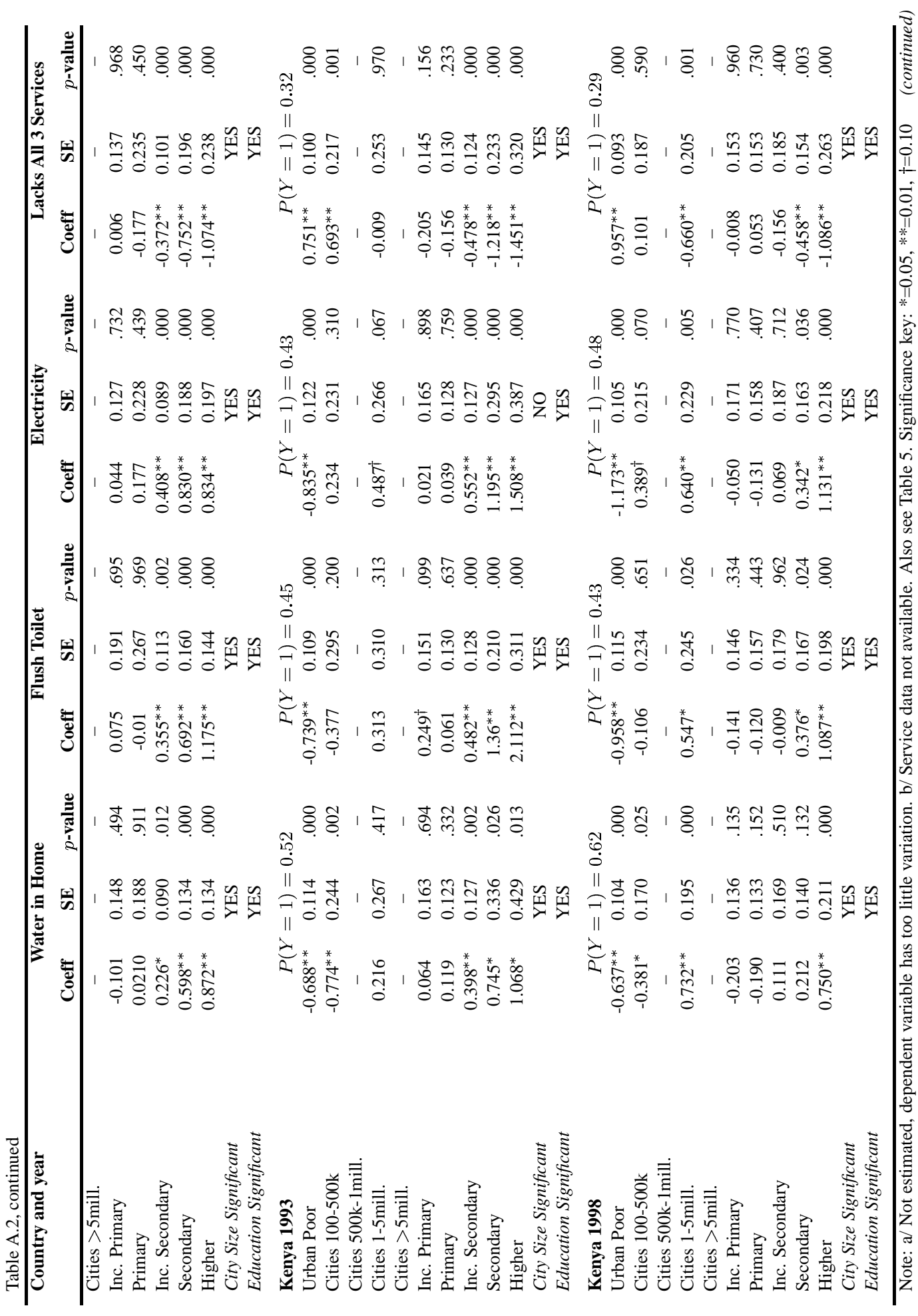




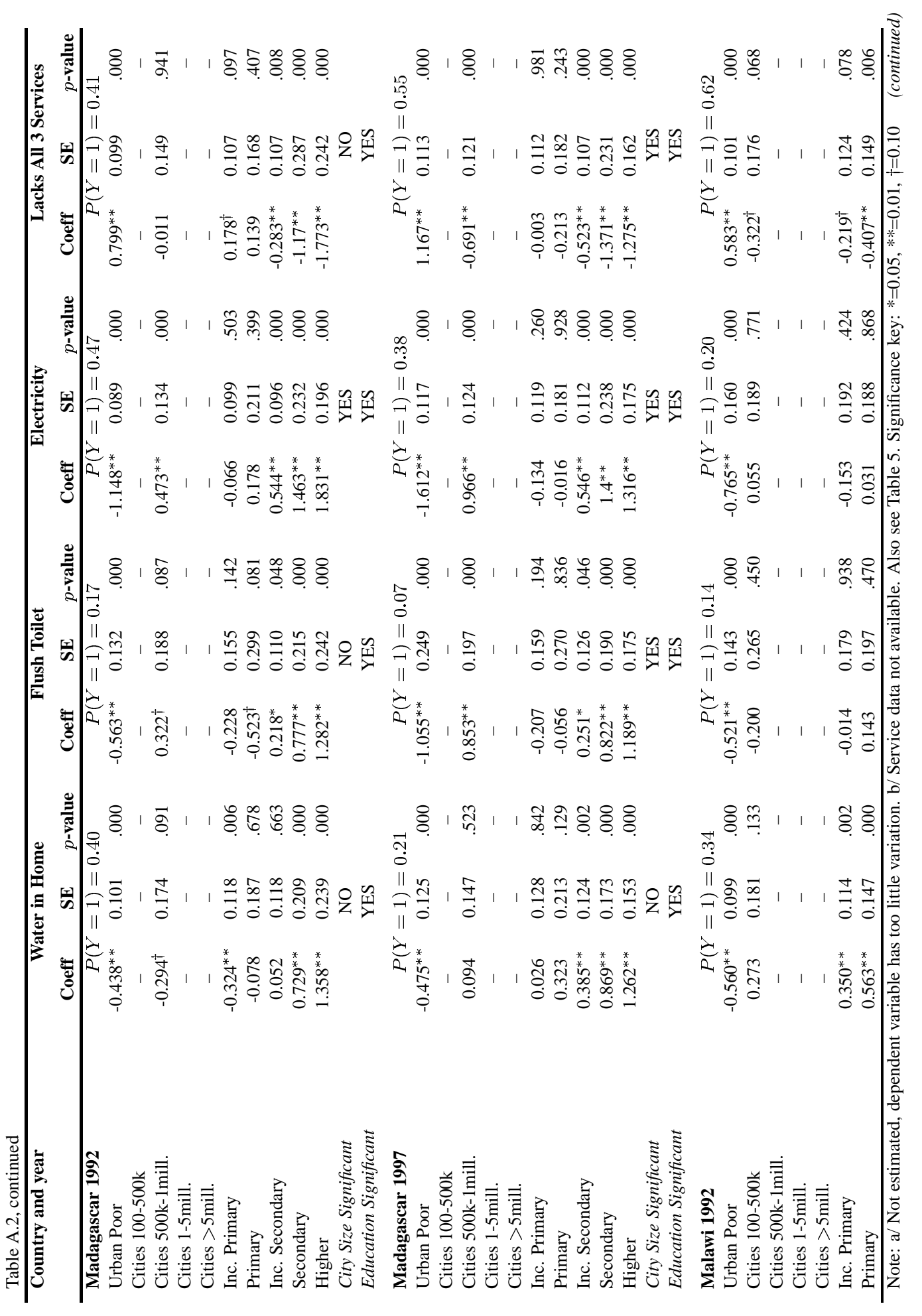




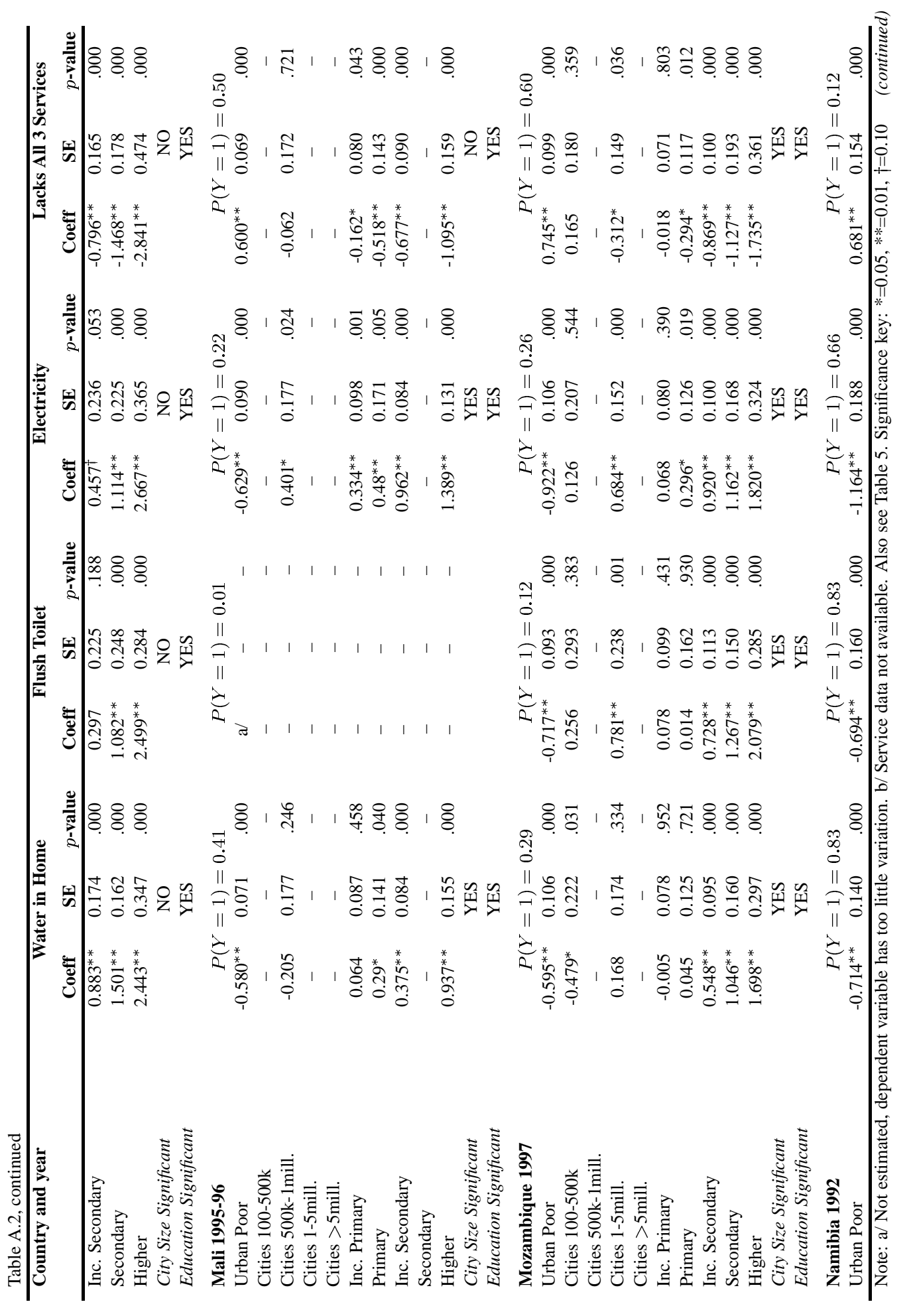




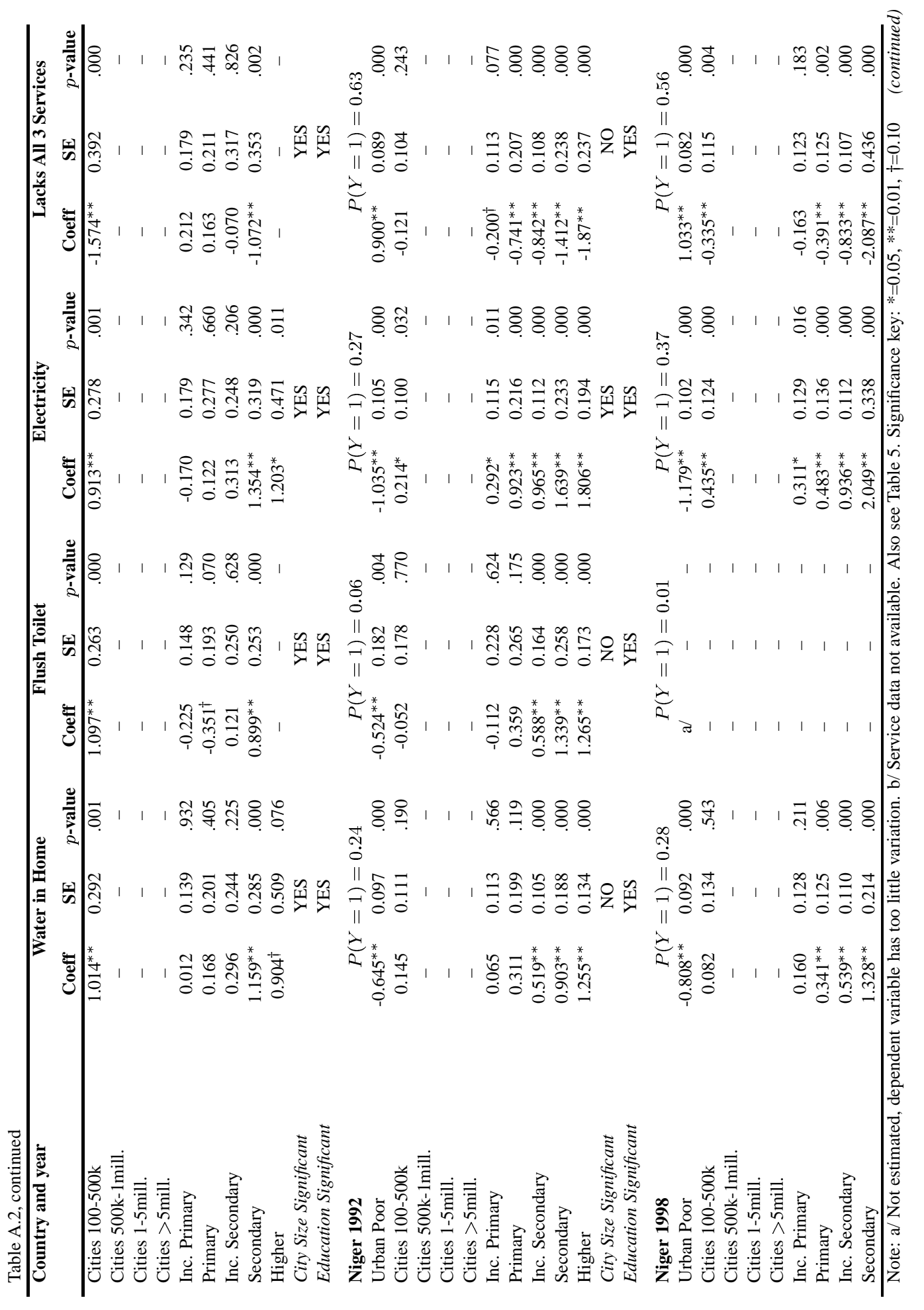




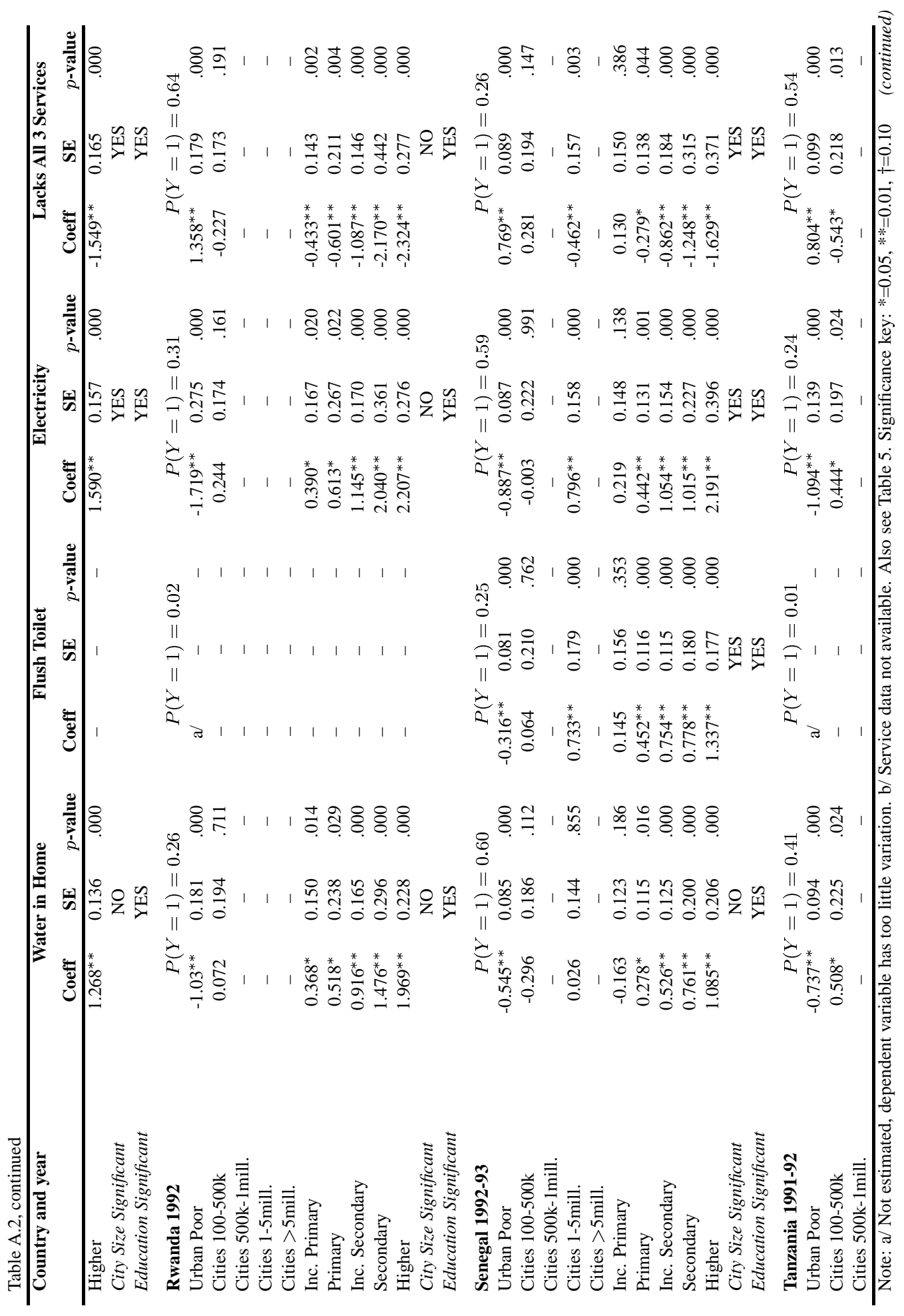




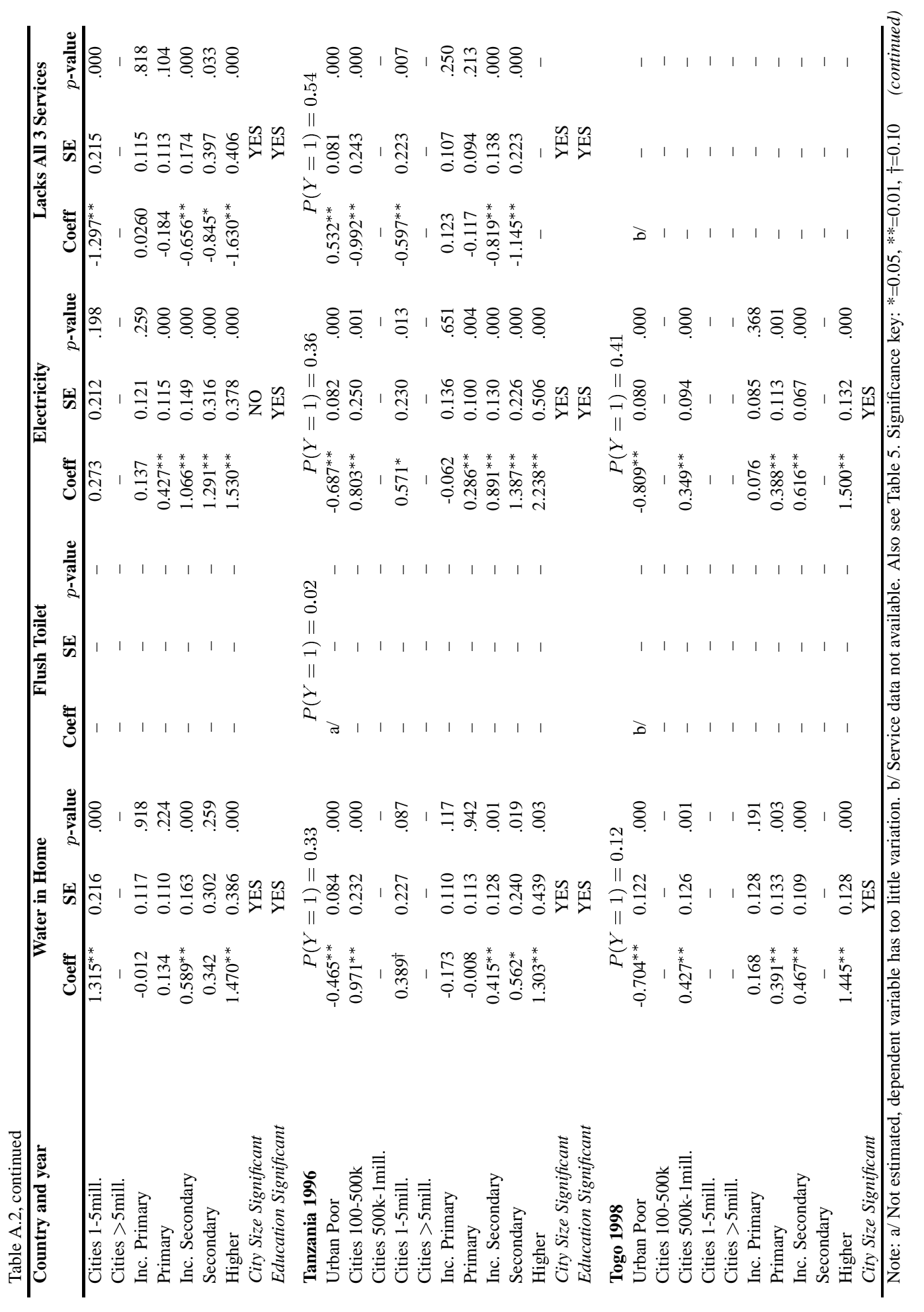




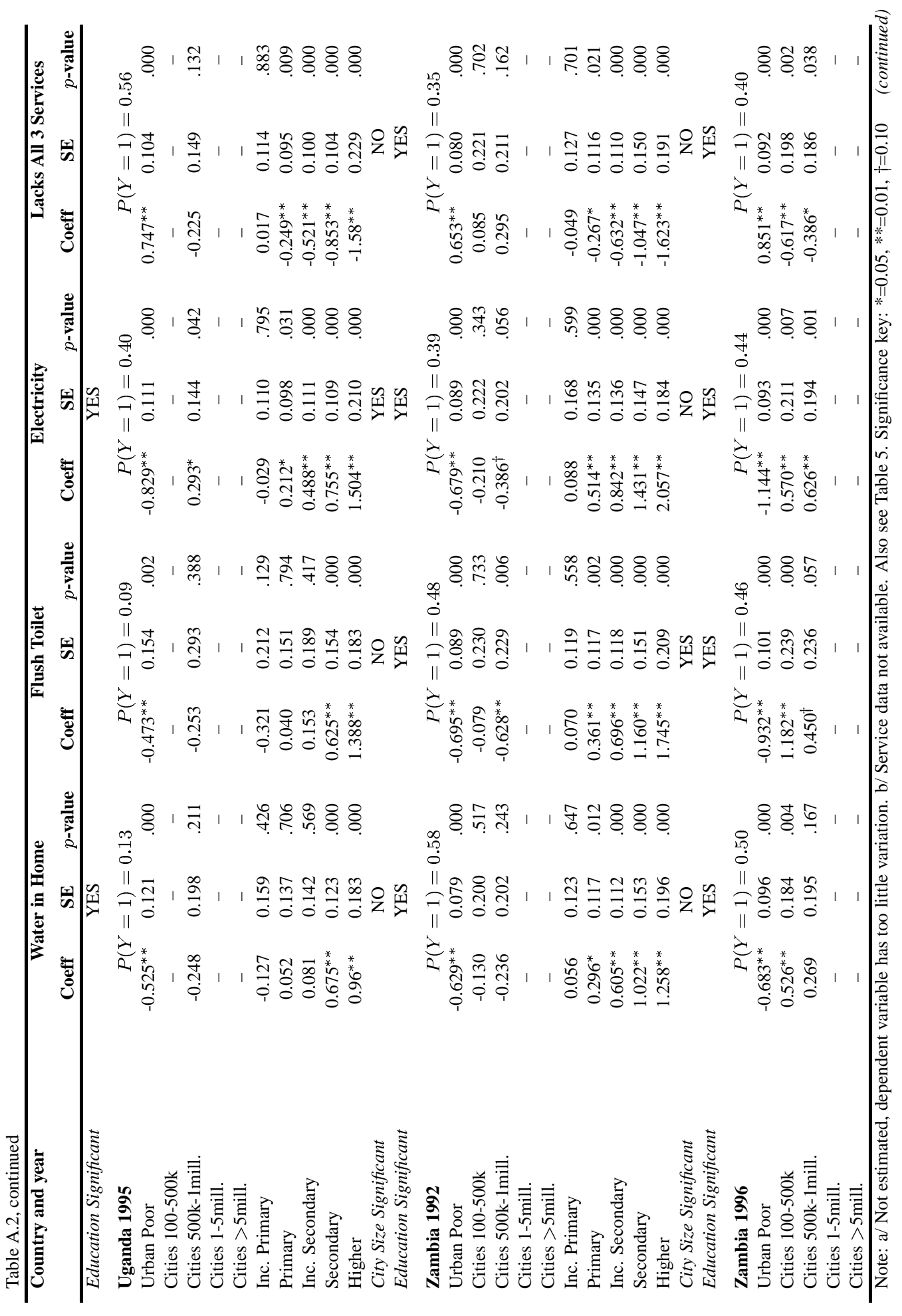




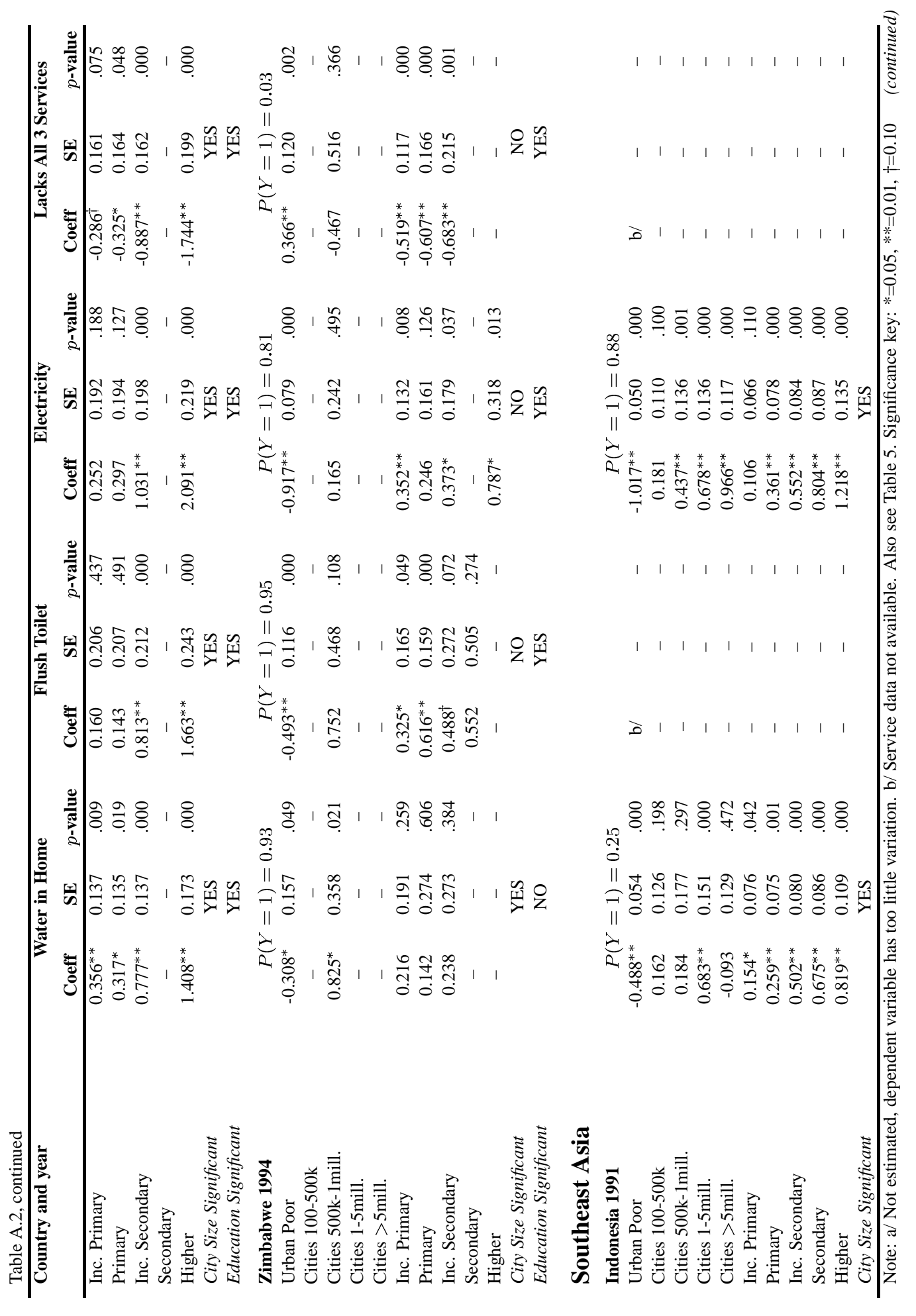




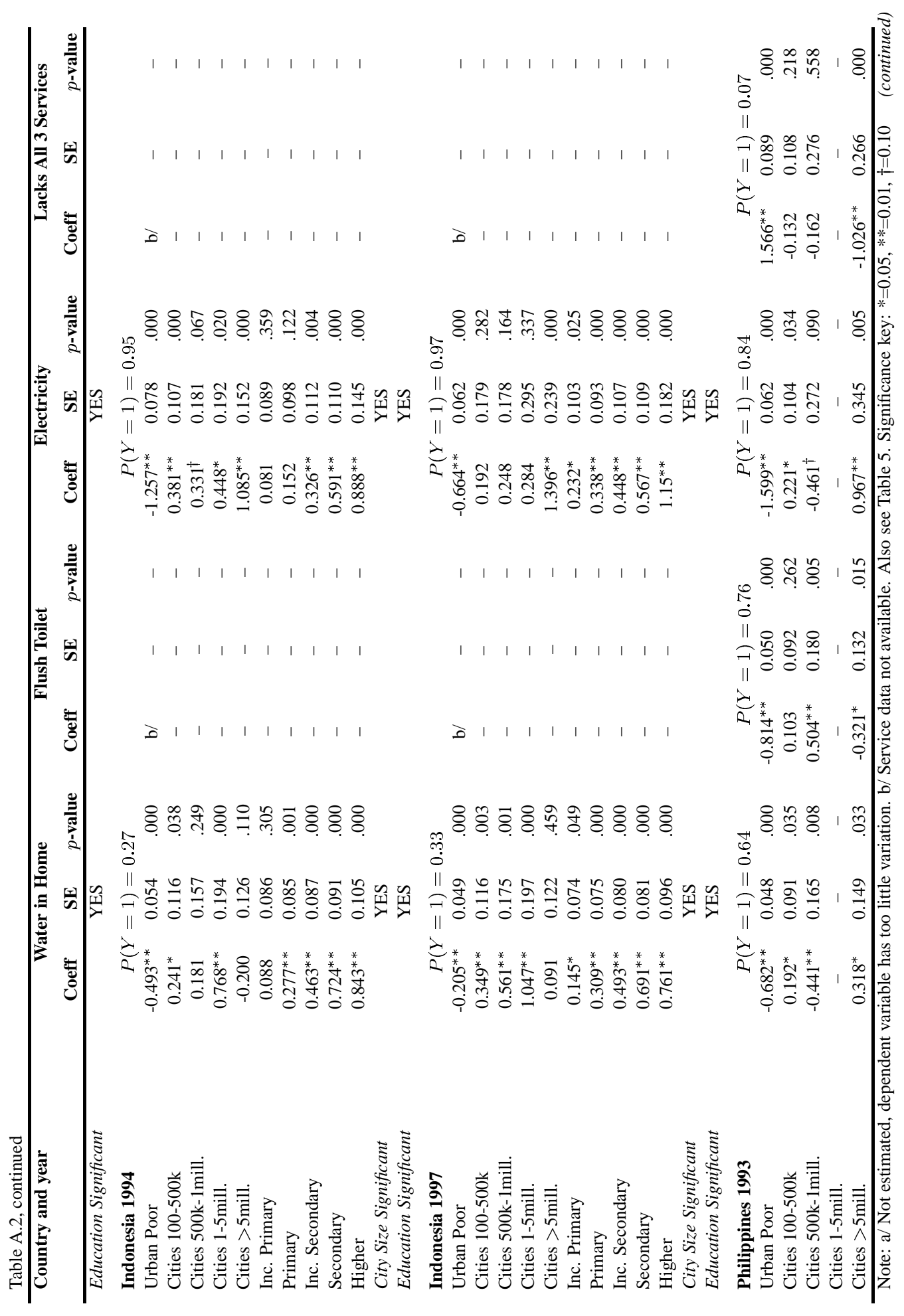




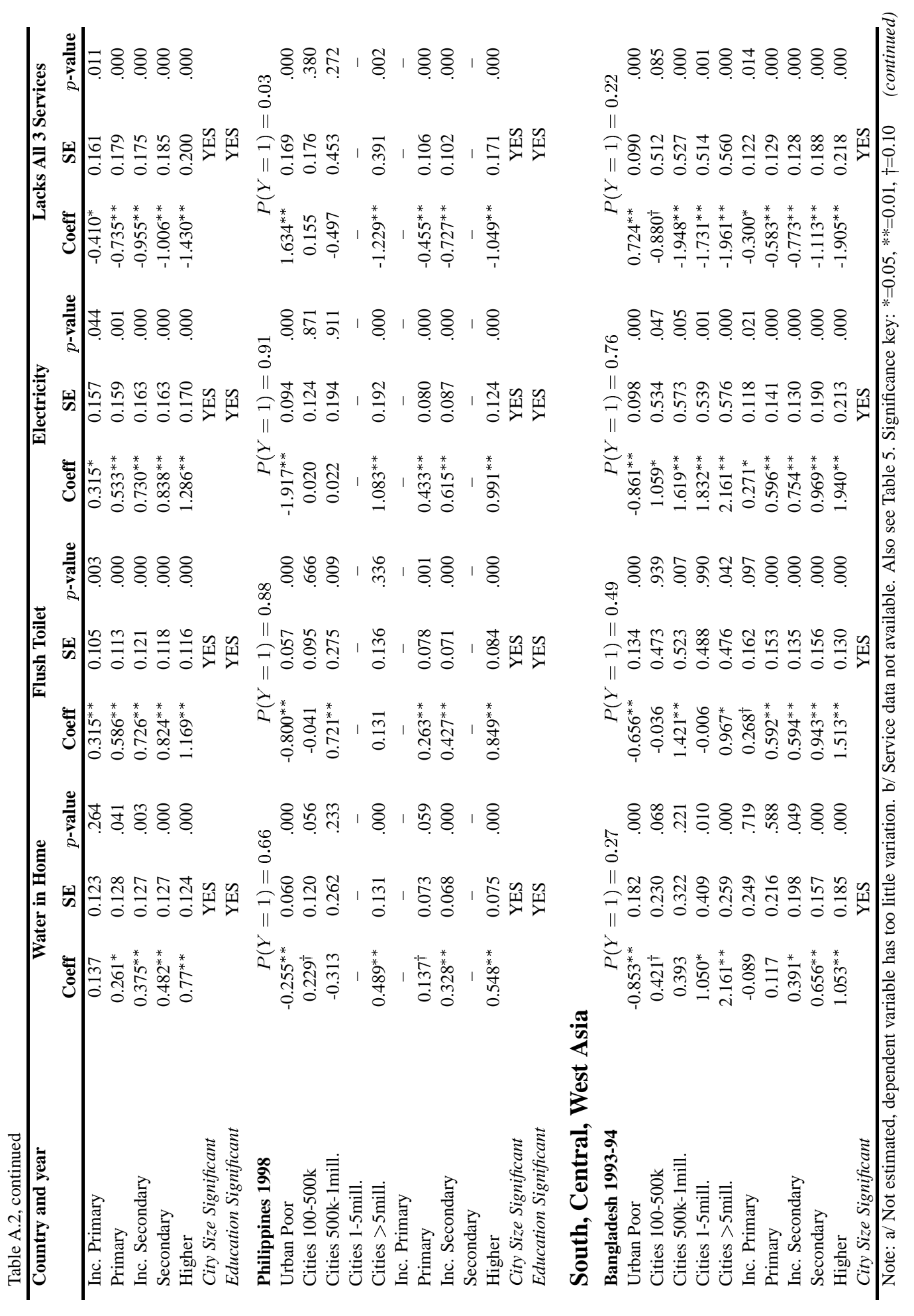




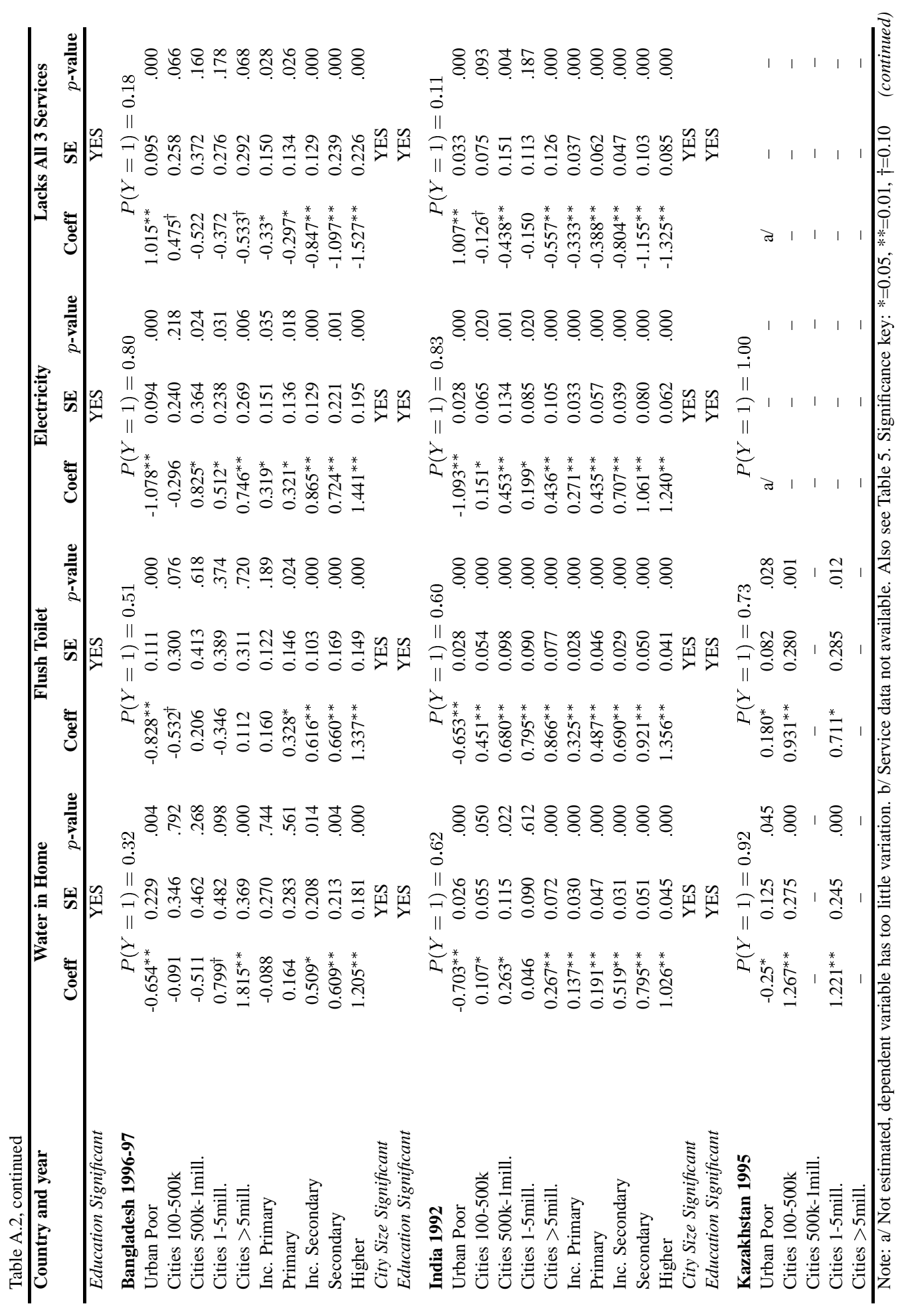




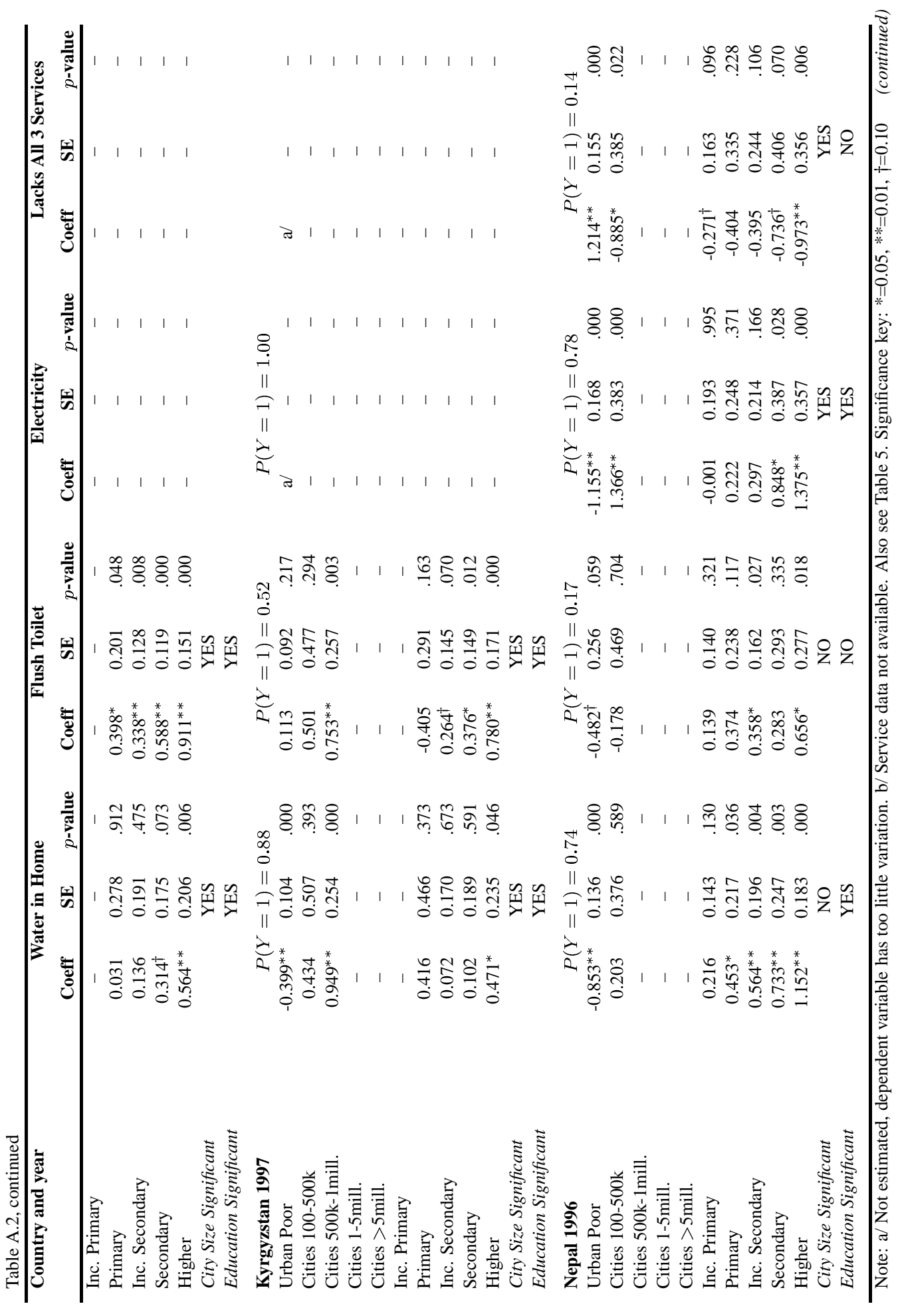




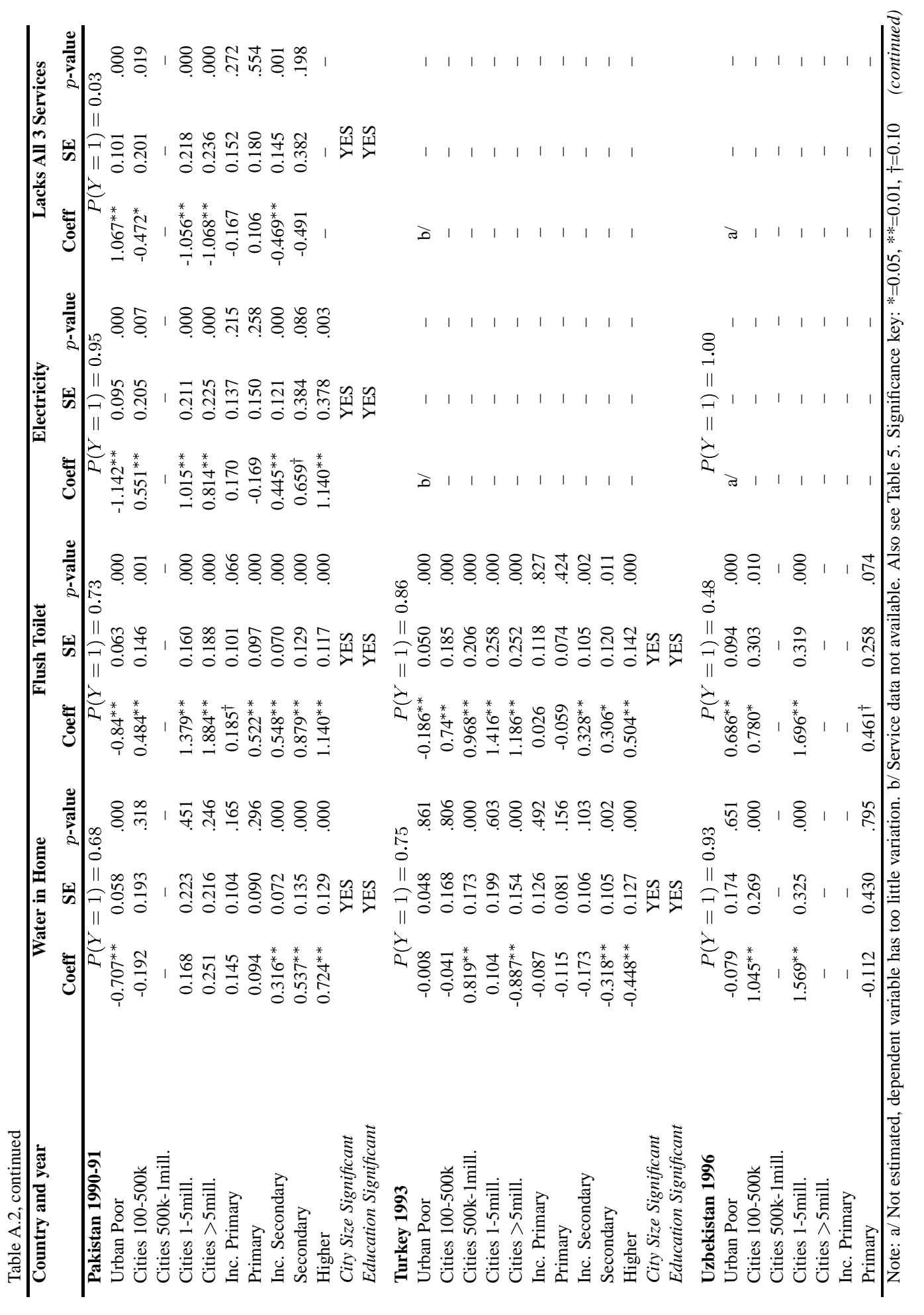




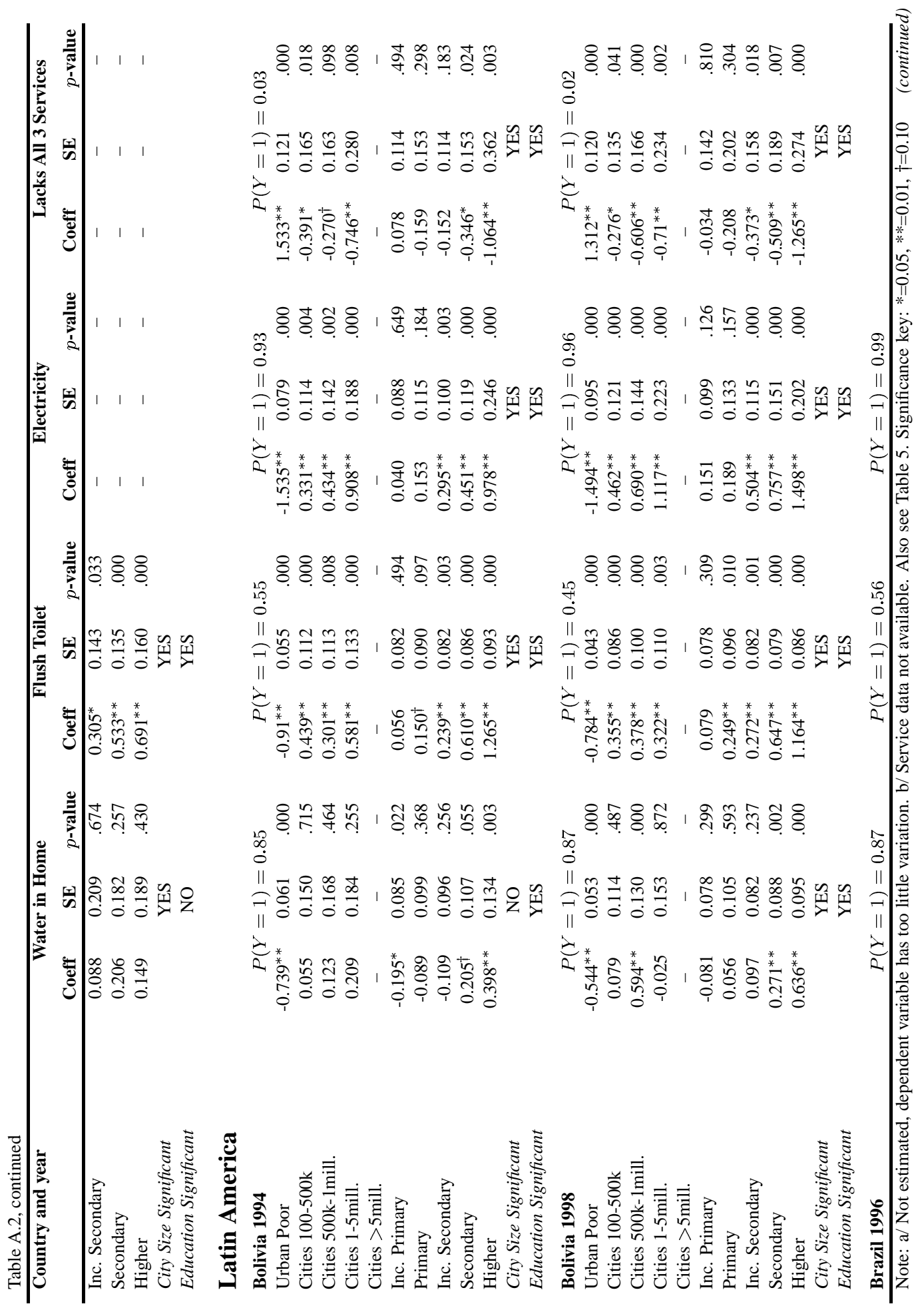




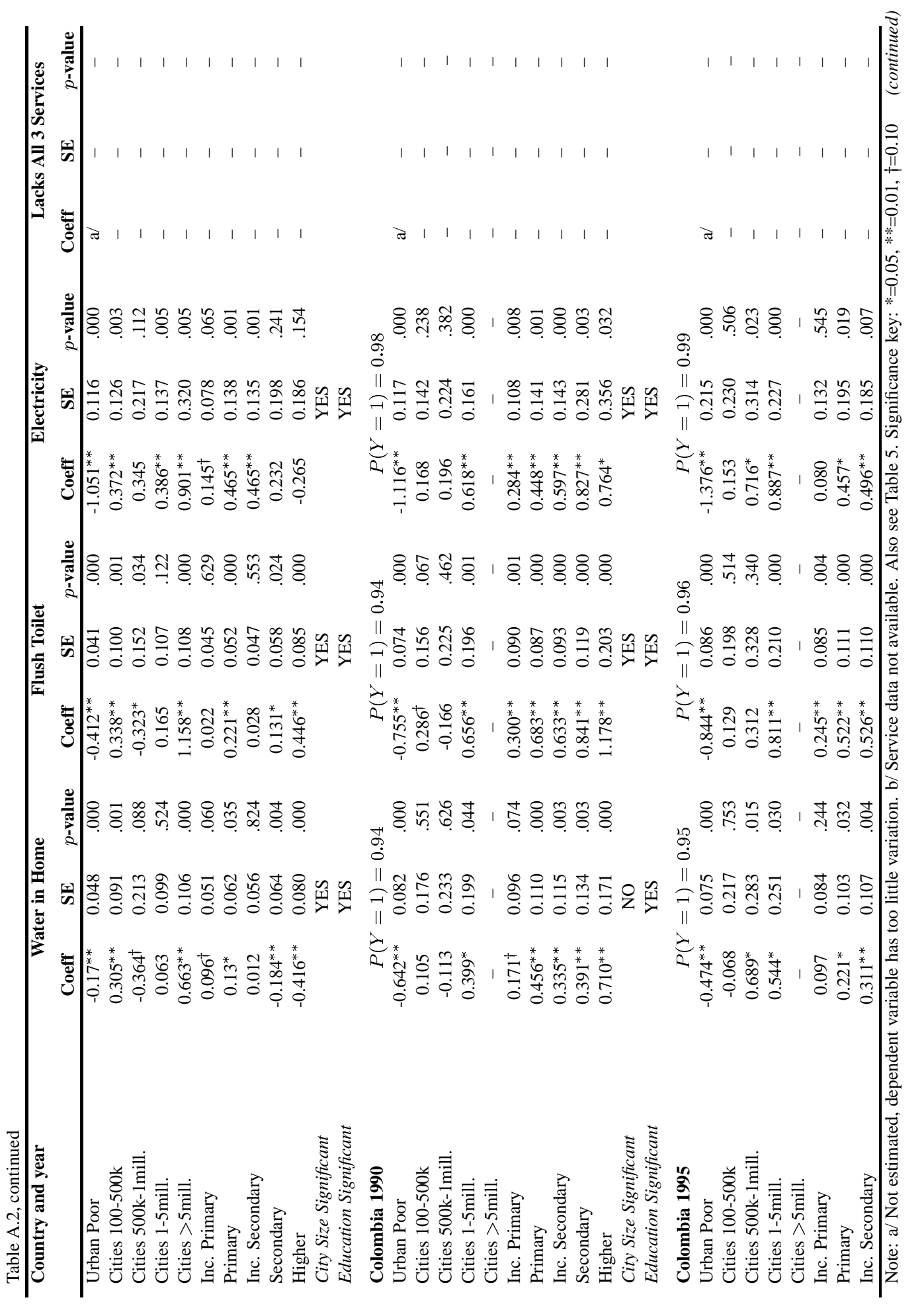




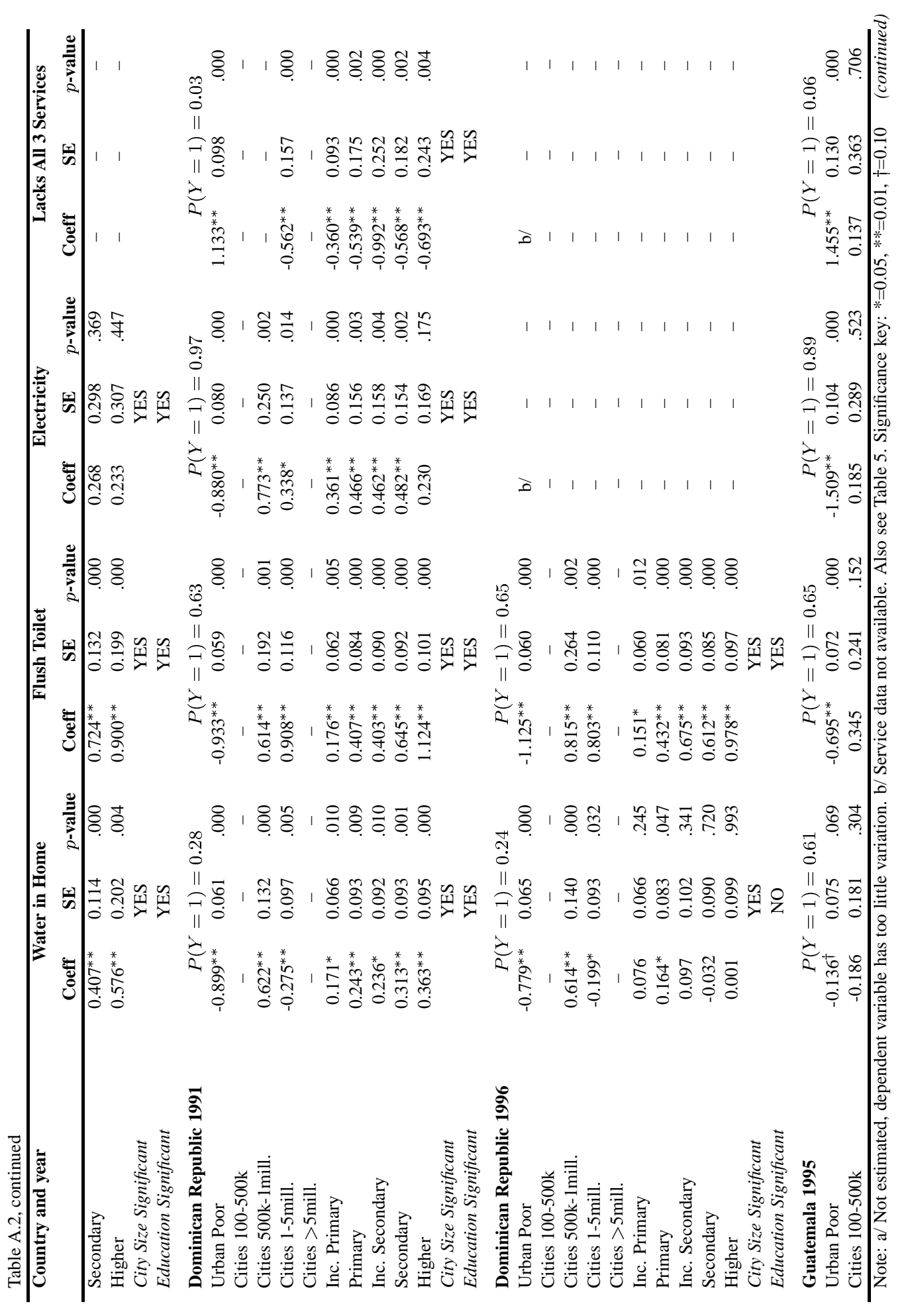




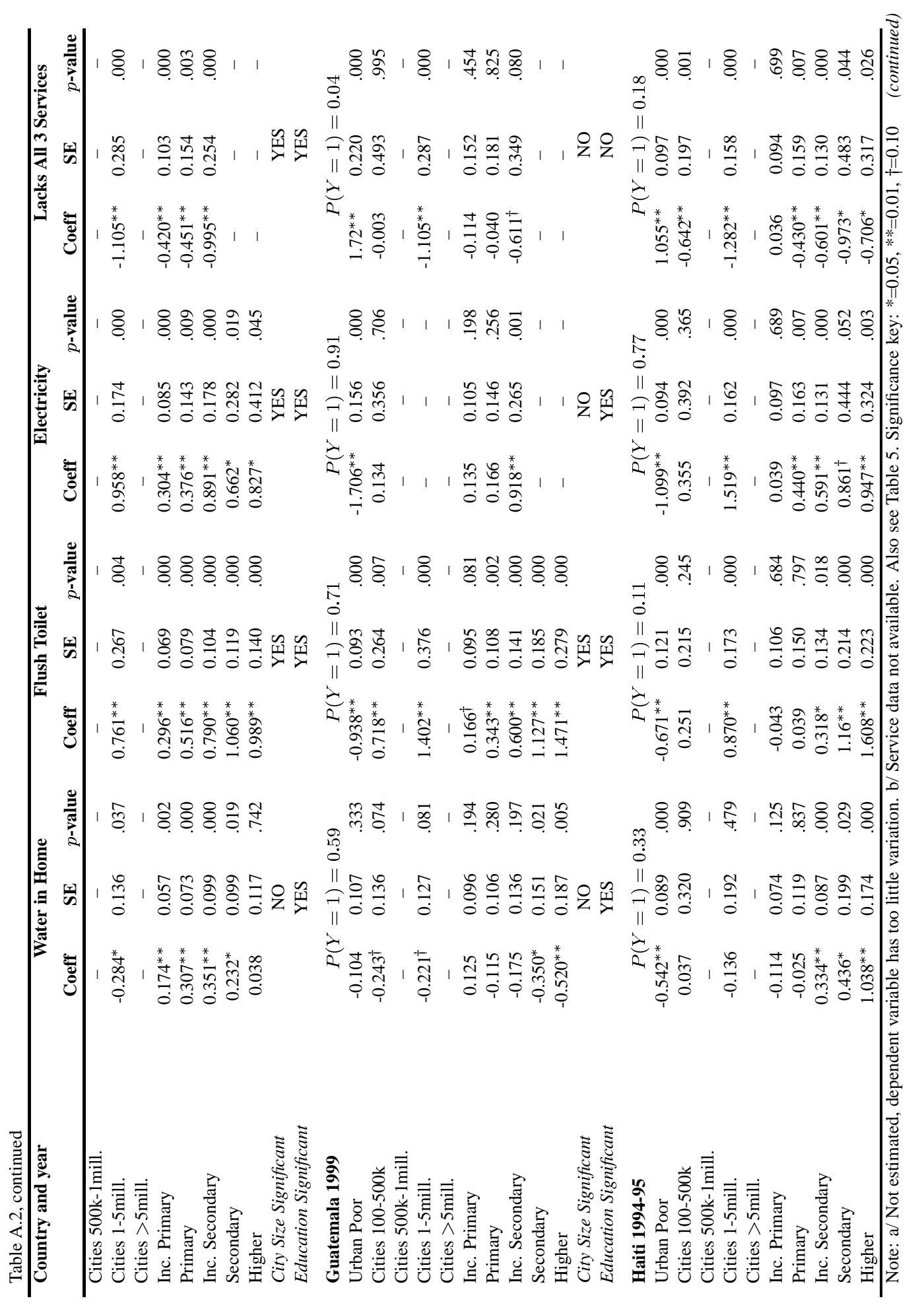




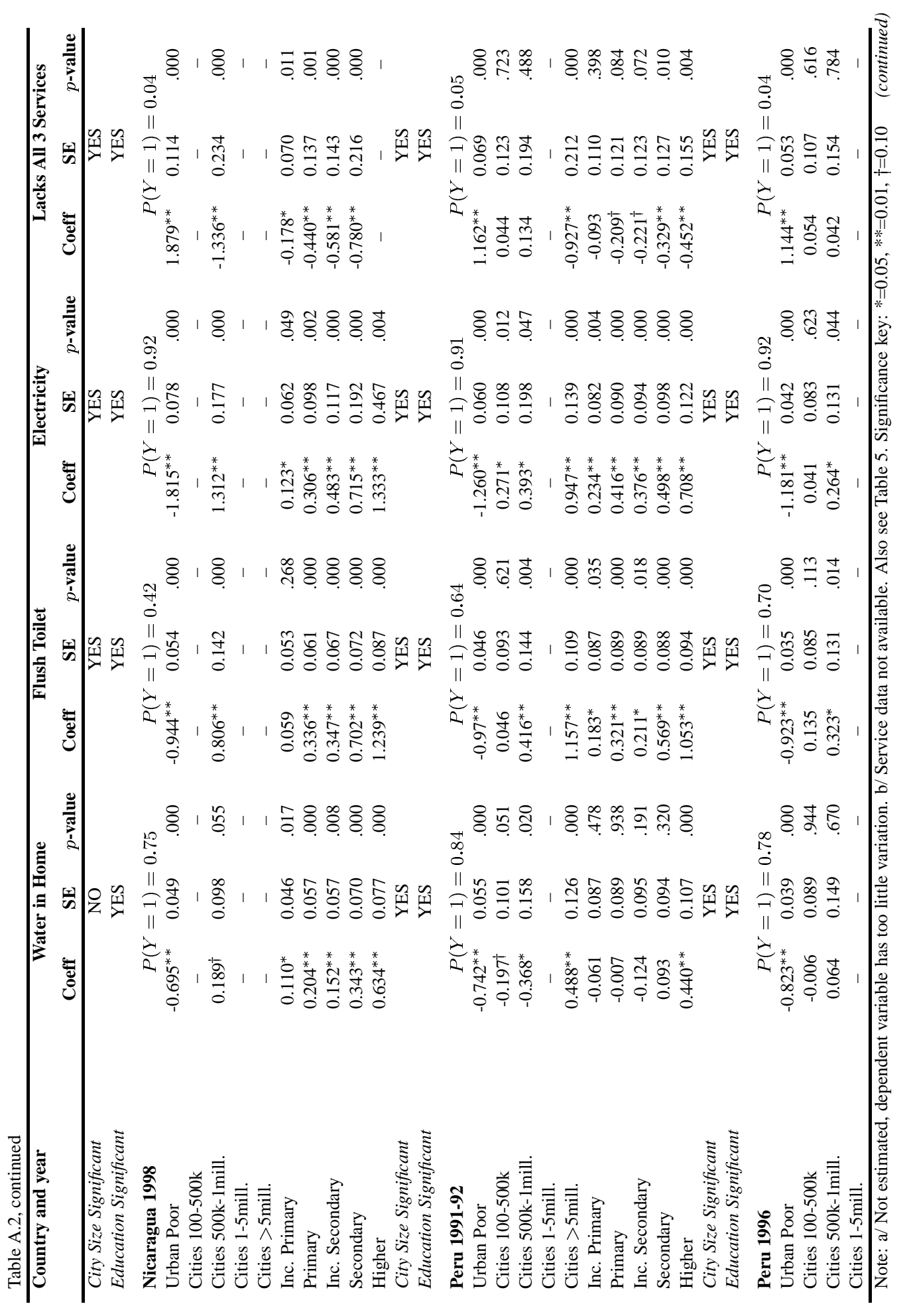




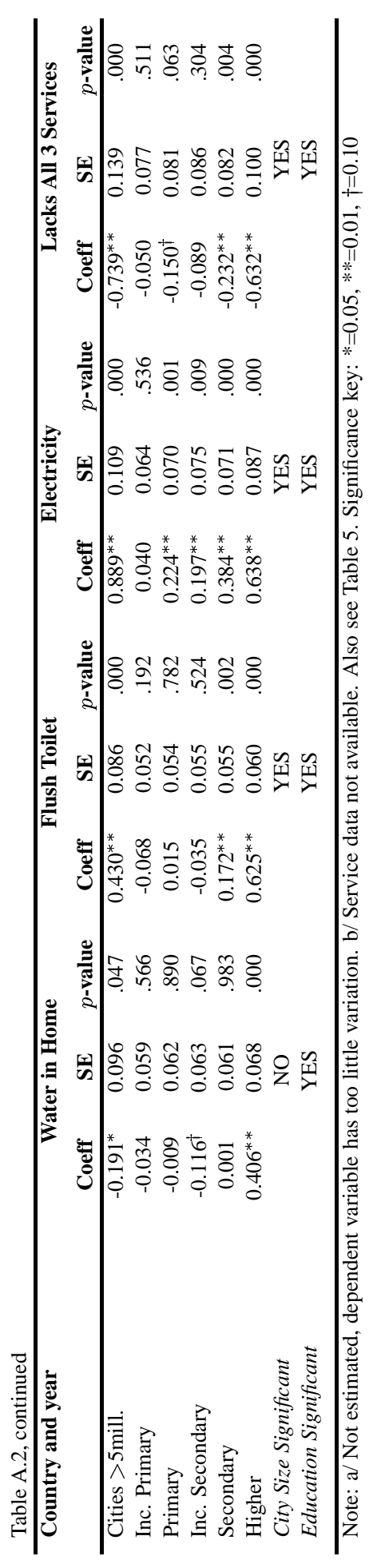




\section{POLICY RESEARCH DIVISION WORKING PAPERS}

Recent Back Issues

1999

*120 John Bongaarts, "The fertility impact of changes in the timing of childbearing in the developing world."

*121 James F. Phillips, Wendy L. Greene, and Elizabeth F. Jackson, "Lessons from community-based distribution of family planning in Africa."

*122 Mark R. Montgomery, "Mortality decline and the demographic response: Toward a new agenda."

*123 Mark R. Montgomery, Mary ArendsKuenning, and Cem Mete, "The quantity-quality transition in Asia."

124 Barbara S. Mensch, Wesley H. Clark, Cynthia B. Lloyd, and Annabel S. Erulkar, "Premarital sex and school dropout in Kenya: Can schools make a difference?"

*125 John Bongaarts and Rodolfo A. Bulatao, "Completing the demographic transition."

126 Geoffrey McNicoll, "Population weights in the international order."
*127 Cynthia B. Lloyd, Carol E. Kaufman, and Paul Hewett, "The spread of primary schooling in sub-Saharan Africa: Implications for fertility change."

128 John B. Casterline, "The onset and pace of fertility transition: National patterns in the second half of the twentieth century."

*129 Mark R. Montgomery, Michele Gragnolati, Kathleen Burke, and Edmundo Paredes, "Measuring living standards with proxy variables."

130 Bamikale Feyisetan and John B. Casterline, "Fertility preferences and contraceptive change in developing countries."

*131 Martin Brockerhoff, "Urban growth in developing countries: A review of projections and predictions."

132 Omaima El-Gibaly, Barbara Ibrahim, Barbara S. Mensch, and Wesley H. Clark, "The decline of female circumcision in Egypt: Evidence and interpretation."

* No longer available 
133 Mary Arends-Kuenning and Sajeda Amin, "The effects of schooling incentive programs on household resource allocation in Bangladesh."

134 John Bongaarts and Charles F. Westoff, "The potential role of contraception in reducing abortion."

135 John B. Casterline and Steven W. Sinding, "Unmet need for family planning in developing countries and implications for population policy."

*136 Carol E. Kaufman, Thea de Wet, and Jonathan Stadler, "Adolescent pregnancy and parenthood in South Africa."

*137 Valerie L. Durrant and Zeba A. Sathar, "Greater investments in children through women's empowerment: A key to demographic change in Pakistan?"

138 Sajeda Amin, Alaka Malwade Basu, and Rob Stephenson, "Spatial variation in contraceptive use in Bangladesh: Looking beyond the borders."
139 Geoffrey McNicoll, "Managing population-environment systems: Problems of institutional design."

140 Barbara S. Mensch, Barbara L. Ibrahim, Susan M. Lee, and Omaima ElGibaly, "Socialization to gender roles and marriage among Egyptian adolescents."

141 John Bongaarts and Elof Johansson, "Future trends in contraception in the developing world: Prevalence and method mix."

142 Alaka Malwade Basu and Sajeda Amin, "Some preconditions for fertility decline in Bengal: History, language identity, and an openness to innovations."

143 Zeba Sathar, Cynthia B. Lloyd, Cem Mete, and Minhaj ul Haque, "Schooling opportunities for girls as a stimulus for fertility change in rural Pakistan."

\footnotetext{
* No longer available
} 
144 John Bongaarts, "Household size and composition in the developing world."

145 John B. Casterline, Zeba A. Sathar, and Minhaj ul Haque, "Obstacles to contraceptive use in Pakistan: A study in Punjab."

146 Zachary Zimmer, Albert I. Hermalin, and Hui-Sheng Lin, "Whose education counts? The impact of grown children's education on the physical functioning of their parents in Taiwan."

147 Philomena Nyarko, Brian Pence, and Cornelius Debpuur, "Immunization status and child survival in rural Ghana."

148 John Bongaarts and Zachary Zimmer, "Living arrangements of older adults in the developing world: An analysis of DHS household surveys."

149 Markos Ezra, "Ecological degradation, rural poverty, and migration in Ethiopia: A contextual analysis."
150 Cynthia B. Lloyd, Sahar El Tawila, Wesley H. Clark, and Barbara S. Mensch, "Determinants of educational attainment among adolescents in Egypt: Does school quality make a difference?"

151 Barbara S. Mensch, Paul C. Hewett, and Annabel Erulkar, " The reporting of sensitive behavior among adolescents: A methodological experiment in Kenya."

152 John Bongaarts, "The end of the fertility transition in the developed world."

153 Mark R. Montgomery, GebreEgziabher Kiros, Dominic Agyeman, John B. Casterline, Peter Aglobitse, and Paul C. Hewett, "Social networks and contraceptive dynamics in southern Ghana."

154 Paul C. Hewett and Mark R. Montgomery, "Poverty and public services in developing-country cities." 
